\section{EDT 603247}

5. Proj./Prog./Dept./Div.:
2. To: (Receiving Organization)

$N / A$
3. From: (Originating Organization)

Nuclear Analysis and Characterization

B. Originator Remarks: HANFURD HLW.

11. Receiver Remarks:

6. cog. Engr.:
WD Wittekind RD Crowe

NAA This documEnt describes the CALIBRATION OF AN

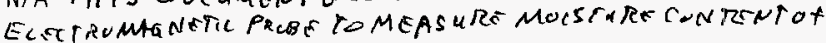

4. Related EDT No.:

$\mathrm{N} / \mathrm{A}$

7. Purchase Order No.:

$\mathrm{N} / \mathrm{A}$

9. Equip./Component No.:

$\mathrm{N} / \mathrm{A}$

10. System/Bldg./Facility:

$N / A$

12. Major Assm. Dwg. No.: $N / A$

13. Permit/Permit Application No.: $N / A$

14. Required Response Date: $N / A$

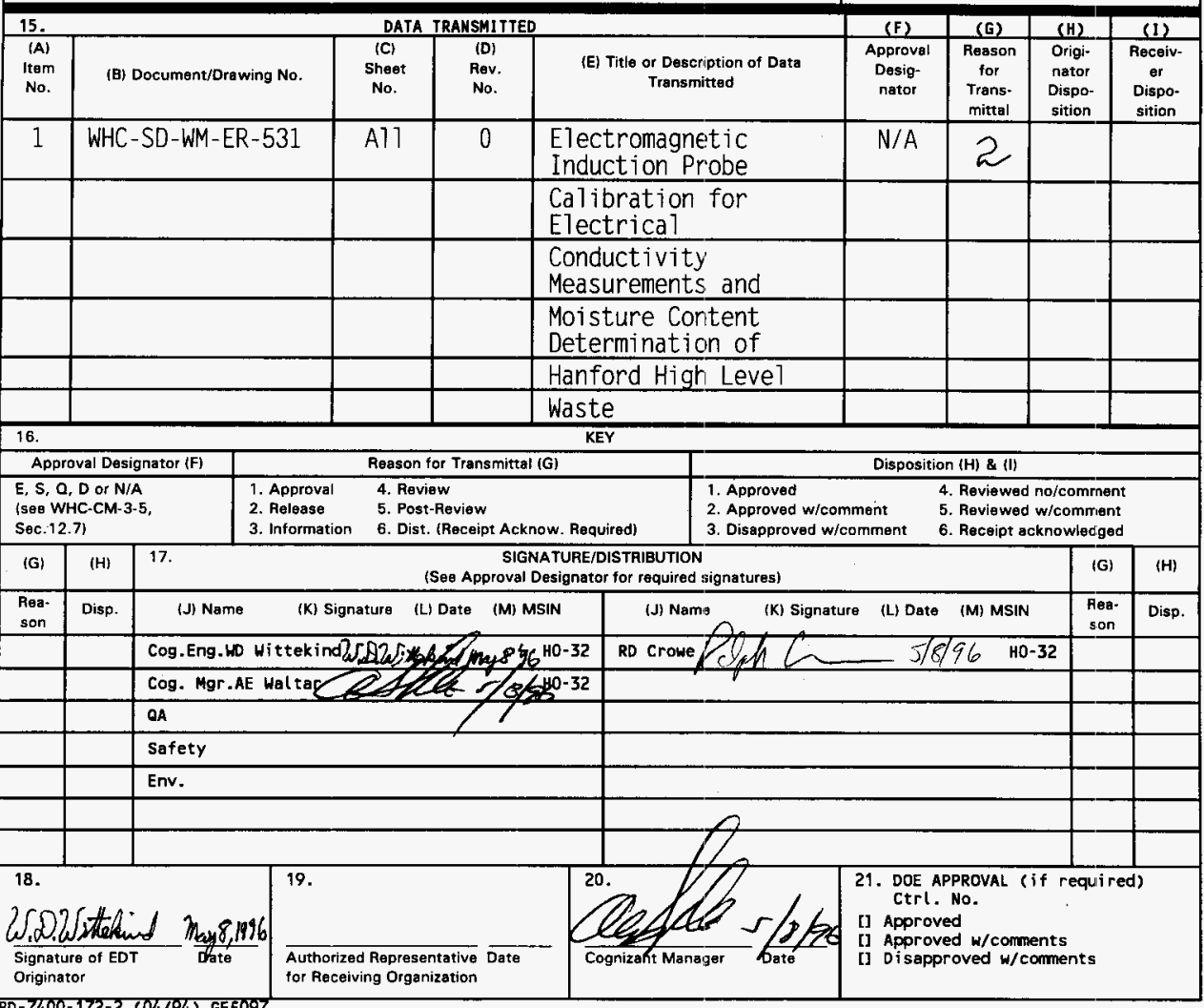




\section{Electromagnetic Induction Probe Calibration for Electrical Conductivity Measurements and Moisture Content Determination of Hanford High Level Waste}

Warren D. Wittekind

Ralph D. Crowe

Westinghouse Hanford Company, Richland. WA 99352

U.S. Department of Energy Contract DE-ACO6-87RL10930

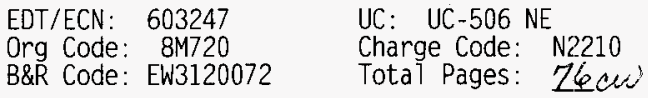

Key Words: Probe, waste tanks, moisture measurements, EMI. Electromagnetic Induction.

Abstract: $\quad$ Logic of converting EMI measured electrical conductivity to moisture with expected uncertainty. Estimates from present knowledge, assumptions, and measured data. Archie's Law has been used since the $1940^{\prime}$ 's to relate electrical conductivity in porous media to liquid volume fraction. Measured electrical conductivity to moisture content uses: Porosity. Interstitial 7iquid electrical conductivity. Solid particle density. Interstitial 7iquid density. and interstitial liquid water content. The uncertainty of assumed values is calculated to determine the final moisture wt.\% result uncertainty.

TRADEMARK DISCLAIMER. Reference herein to any specific comercial product, process, or service by trade name, trademark, manufacturer, or otherwise, does not necessarily constitute or imply its endorsement, recommendation, or favoring by the United States Government or any agency thereof or its contractors or subcontractors.

Printed in the United States of America. To obtain copies of this document, contact: WHC/BCS Document Control Services, P.O. Box 1970, Mailstop H6-08, Richland WA 99352, Phone (509) 372-2420; Fax (509) 376-4989.
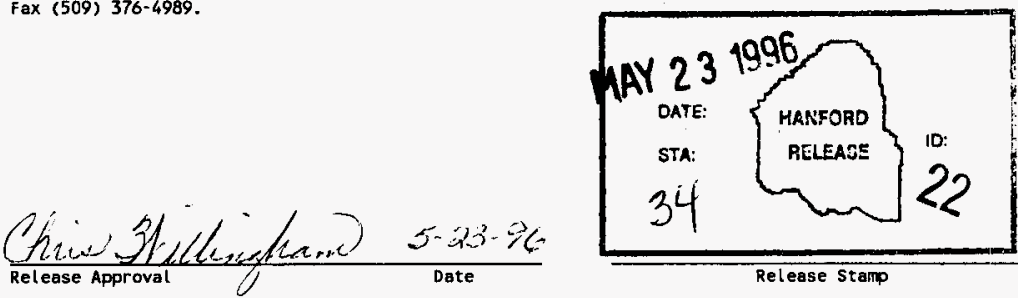

Rel ease Stamp 


\section{Electromagnetic Induction Probe Calibration for Electrical Conductivity Measurements and Moisture Content Determination of Hanford High Level Waste}

W. D. Wittekind

R. D. Crowe

Date Published

May 1996

Prepared for the U.S. Department of Energy Assistant Secretary for Environmental Management

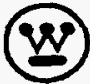

Westinghouse

P.O Box 1970

Hanford Company Richland, Washington

Management and Operations Contractor for the

U.S. Department of Energy under Contract DE-ACO6-87RL 10930

Copyright Lisenes By acceptence of this article, the publisher end/or recipient acknowledges the

U.S. Government's right to retain a nonexclusive, royalty-free license in and to any copyright covering this paper.

Approved for public release; distribution is unlimited 


\section{ELECTROMAGNETIC INDUCTION PROBE CALIBRATION FOR ELECTRICAL CONDUCTIVITY MEASURENENTS AND MOISTURE CONTENT DETERMINATION OF HANFORD HIGH LEVEL WASTE Revision 0}

WHC-SD-WH-ER-531

Prepared by

Warren D. Wittekind

Ralph D. Crowe

May 1996 
WHC-SD-WM-ER-531 REV 0

This page intentionally left blank. 


\section{ABSTRACT}

This report demonstrates the logic of converting electromagnetic induction measured electrical conductivity to moisture. The report shows the expected uncertainty in the measurements by using the uncertainty of all the factors in the calculations.

This report is based on best estimates from present knowledge, assumptions (assumptions are checked/validated when possible), and measured data.

The basis for converting measured electrical conductivity to moisture content is known as Archie's Law (Archie 1942). This law has been used by Geophysicists since the 1940's to relate electrical conductivity in porous media to interstitial liquid conductivity, porous volume, and liquid volume fraction.

The conversion of measured electrical conductivity to moisture content uses assumed values for the following:

- Porosity

- Interstitial liquid electrical conductivity

- Solid particle density

- Interstitial liquid density, and interstitial liquid water content.

The uncertainty of each of these assumed values is calculated to determine the moisture $w t \%$. The results are shown in the following table. 


\begin{tabular}{|c|c|c|}
\hline \multicolumn{3}{|c|}{$\begin{array}{c}\text { Electromagnetic Induction Inferred Moisture } \\
\text { Content with Uncertainties }\end{array}$} \\
\hline $\begin{array}{c}\text { Matrix conductivity } \\
\text { mS/cm }\end{array}$ & $\begin{array}{c}\text { Moisture content } \\
\text { wt\% } \mathrm{H}_{2} \mathrm{O}\end{array}$ & $\begin{array}{c}\text { Uncertainty } \\
\text { wt\% } \mathrm{H}_{2} \mathrm{O}\end{array}$ \\
\hline 80 & 26.8 & \pm 5.8 \\
\hline 60 & 24.3 & \pm 5.3 \\
\hline 40 & 21.0 & \pm 4.6 \\
\hline 20 & 16.1 & \pm 3.6 \\
\hline 10 & 12.1 & \pm 2.8 \\
\hline 5 & 9.0 & \pm 2.1 \\
\hline
\end{tabular}

Porosity $\theta=0.50$ uncertainty +0.05

$\begin{array}{ll}\sigma_{\mathrm{H}} & =200 \mathrm{mS} / \mathrm{cm}^{3} \text { uncertainty } \pm 25 \mathrm{mS} / \mathrm{cm} \\ \rho_{\mathrm{S}} & =2.20 \mathrm{~g} / \mathrm{cm}^{3} \text { uncertainty } \pm 0.10 \mathrm{~g} / \mathrm{cm}^{3} \\ \rho_{\mathrm{L}} & =1.18 \mathrm{~g} / \mathrm{cm}^{3} \text { uncertainty } \pm 0.09 \mathrm{~g} / \mathrm{cm}^{3} \\ \left(\rho_{2} \mathrm{O} / \rho_{\mathrm{L}}\right) & =0.79 \text { uncertainty } \pm 0.11 .\end{array}$




\section{CONTENTS}

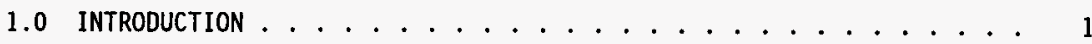

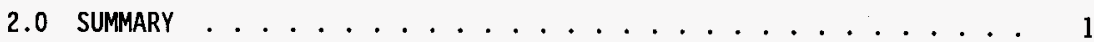

3.0 THEORY OF ELECTROMAGNETIC INDUCTION MOISTURE MEASUREMENT . . . . . . 2

3.1 EDDY CURRENTS.... .2

3.2 ELECTROMAGNETIC INDUCTION MEASUREMENT OF ELECTRICAL

3.3 ELECTRICAL CONDUCTIVITY DEPENDENCE ON MOISTURE CONTENT $\cdots \cdots$

3.3.1 Electrical Conductivity of Electrolytic Solutions $: \cdots 9$

3.3.2 Electrical Conductivity Solution Modeling ...... 11

4.0 WASTE GEOMETRY DESCRIPTION .................. 13

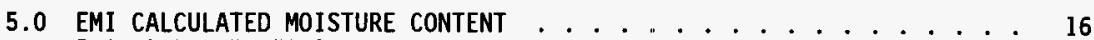

5.1 POROSITY EFFECT . . . . . . . . . . . . . . . . 19

5.2 INTERSTITIAL LIQUID CONDUCTIVITY EFFECT . . . . . . . . 20

5.3 SOLID PARTICLE DENSITY EFFECT . . . . . . . 21

5.4 INTERSTITIAL LIQUID DENSITY AND WATER FRACTION EFFECT $\ldots \ldots . .22$

5.5 ARCHIE'S LAW PARAMETER VALUES EFFECT ............ 23

6.0 EVAlUation AND RESUlts .................. 25

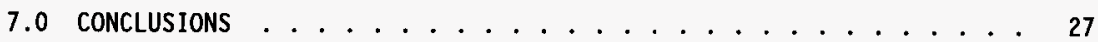

8.0 REFERENCES ...................... 27

9.0 ACKNOWLEDGEMENTS .................... 29

\section{APPENDIXES}

A TEMPERATURE DISTRIBUTION CALCULATION FOR A LIQUID

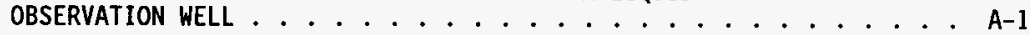

B ARCHIE'S LAW STATUS AND CHOICE OF CONSTANTS . . . . . . . . . B-1

C LIQUID DENSITY AND WATER FRACTION CALCULATION . . . . . . . . c-1

D REVIEW COMMENT RECORD FOR INDEPENDENT REVIEW . . . . . . . . . D-1 
WHC-SD-WM-ER-531 REV 0

\section{LIST OF FIGURE\$}

1 EMI Probe Driver Pickup Phase Lag Relationships ......... . 4

2 EMI Eddy Current Electronic Components ............. 6

3 EMI Laboratory Test Stands . . . . . . . . . . . . . 7

4 Electrical Conductivity Between Pure Water and Fused Salt . . . . 8

\section{LIST OF TABLES}

1 Ionic Conductivity for Relevant Ions .............. 10

2 Electrical Conductivity Regression Coefficients ......... 12

3 Predicted Electrical Conductivity of Analyzed Compositions . . . . . 12

4 Forms of Archie's Law for Some Sedimentary Rocks . . . . . . . . . 15

5 Porosity Effect on EMI Inferred Moisture Content . . . . . . . 19

6 Liquid Electrical Conductivity Effect on EMI Moisture Content . . . 20

7 Solid Density of HLW Components . . . . . . . . . . . . . 21

8 Solid Density Effect on EMI Inferred Moisture Content ....... 22

9 Liquid Density Effects on EMI Inferred Moisture Content . . . . . 23

10 Archie's Law Parameters Effect on EMI Inferred Moisture Content . . 25

11 EMI Inferred Moisture Content with Uncertainties . . . . . . . . 26 
WHC-SD-WM-ER-531 REV 0

\section{LIST OF TERMS}

EMI

HLW

electromagnetic induction

high-level waste

1 iquid observation well

WHC

Westinghouse Hanford Company

vii 
WHC-SD-WM-ER-531 REV 0

This page intentionally left blank. 


\section{ELECTROMAGNETIC INDUCTION PROBE CALIBRATION FOR ELECTRICAL CONDUCTIVITY MEASUREMENTS AND MOISTURE CONTENT DETERMINATION OF HANFORD HIGH LEVEL WASTE}

\subsection{INTRODUCTION}

An electromagnetic induction (EMI) probe is being developed by the Westinghouse Hanford Company (WHC) (Crowe and Wittekind 1995) to measure the amount of water remaining in waste stored in the high-level waste tanks on the Hanford Site. The electromagnetic probe uses a magnetic field to induce electrical current in the surrounding waste proportional to the waste conductivity. The moisture content of the waste is estimated based on the measured waste conductivity. The primary factors that influence the electrical resistance or conductance of the waste are porosity, waste liquid content, waste liquid chemistry, and temperature.

\subsection{SUMMARY}

This report provides details about EMI work in progress, descriptions of calculations used to convert EMI conductivity measurements into moisture content by weight, and success to date.

The basis for converting EMI measured electrical conductivity to liquid volume content is known as Archie's Law. Since the 1940's this law has been used in geophysics to relate electrical conductivity in porous media with electrolyte conductivity, porous volume, and liquid volume fractions.

To calculate the moisture content by weight fraction from liquid volume fraction requires additional values for salt-saturated interstitial liquid electrical conductivity, solid particle density, interstitial liquid density, and interstitial liquid water fraction. There are uncertainties for each of the physical values used in the weight fraction moisture content calculation.

The EMI method measures average matrix electrical conductivity that can be correlated to moisture content.

The calibration of the measured electrical conductivity to moisture content determination depends on the following physical properties:

- Solid porosity (absolute porosity, not drainable porosity)

- Interstitial liquid electrical conductivity (major dependency on temperature, and lesser dependency on matrix composition)

- Solid (salt grain particle) density 
- Interstitial liquid density

- Interstitial liquid water fraction (weight fraction of $\mathrm{H}_{2} \mathrm{O}$ in salt-saturated liquid).

Fundamental mathematical equations are explained, numerical values of each parameter and their uncertainties are calculated, and their effects on the moisture content by weight and its total uncertainty is calculated.

The following are unique advantages of an EMI approach to water content measurements:

- Very sensitive to loss of hydraulic conductivity

- Infers free-water content, because electrical conductivity is not affected by chemically bound water.

\subsection{THEORY OF ELECTROMAGNETIC INDUCTION MOISTURE MEASUREMENT}

Theory of EMI moisture measurement is discussed in Sections 3.2 and 3.3 .

\subsection{EDDY CURRENTS}

When a magnetic field moves through a conductive medium it induces electrical currents in the medium. The inductive method uses a driver coil made of wire with an alternating current flowing through the driver coil to set up an alternating magnetic field that induces eddy current flow in the surrounding material. These induced currents generate a secondary magnetic field that creates an induced current in the pickup coil positioned along the axis of the first coil. The pickup coil has induced currents arising from the eddy currents generated by the original magnetic field and al so from the secondary magnetic field from eddy currents in the medium. The secondary magnetic field induced is $180^{\circ}$ out-of-phase with the original field. The induced current from the primary magnetic field can be eliminated by designing electronics to produce a signal proportional to the conductivity of the surrounding medium.

The magnitude of the primary magnetic field is proportional to the current in the primary or transmitting coil. The induced eddy currents are proportional to the magnetic field strength of the primary field and the conductivity of the waste. The secondary magnetic field strength from the eddy currents and the induced current in the receiver coil is proportional to the waste conductivity. It is useful to recognize that the electromagnetic energy coupled between the coils is subjected to attenuation and phase-shift as it propagates. We can define a "skin depth" as a measure of the distance that a propagating wave will penetrate. 


$$
\Psi=e^{-\frac{x}{\delta}} e^{i\left(\frac{x}{\delta}(t)\right.}
$$

where

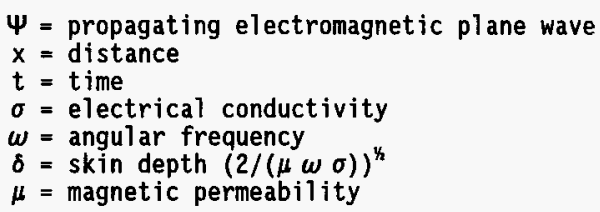

Skin depth is a function of frequency and conductivity (or resistance). The propagating wave loses energy to the currents induced in the waste. The more conductive the waste the greater the currents, and the shorter the distance the field travels. For frequencies from 50 to $200 \mathrm{kHz}$, the skin depth in the waste is about 50 to $100 \mathrm{~cm}$.

The waste conducts an electrical current depending on its electrical resistance. The electrical resistance depends on the geometry of the current flow, and the resistivity of the waste. Resistivity is a fundamental property of the material and has units of ohm-meters. Conductivity is the reciprocal of resistivity and has units of inverse ohm-meters, or equivalent, Siemens per meter. When the liquid and solids in the waste are considered resistors in parallel, most of the current flows through the medium with the lower resistance. Consequently, current flow in the waste is primarily confined to the fluid within the pore spaces. The resistance or conductance of a material is descriptive of the character of the pore space, and of the properties of the interstitial liquid filling the pore space.

\subsection{ELECTROMAGNETIC INDUCTION MEASUREMENT OF ELECTRICAL CONDUCTIVITY}

The EMI measurement of electrical conductivity depends on the driver coil alternating current and the induced voltage in the pickup coil. Therefore the induced electrical field has a $90^{\circ}$ phase lag behind the driver coil electrical field. When a direct induced electrical field in the pickup coils or adjacent conductive medium is created, a direct induced voltage that is $90^{\circ}$ outof-phase with the driving coil is generated. The induced current in the medium induces a secondary voltage in the pickup coil that lags $90^{\circ}$ behind the induced electrical current, or $180^{\circ}$ phase 1 ag behind the driver coil. These phase lag relationships are illustrated in Figure 1.

There are two pickup coil induced voltages; driver coil direct inductance that lags $90^{\circ}$ in phase behind, and an indirect inductance that lags $180^{\circ}$ in phase behind the driver coil current and depends on medium electrical conductivity. A phase sensitive impedance meter separates the two phases and determines the medium conductivity signal magnitude. 
Figure 1. EMI Probe Driver Pickup Phase Lag Relationships.

\section{EMI Probe Driver Pickup Phase Lag Relationships}
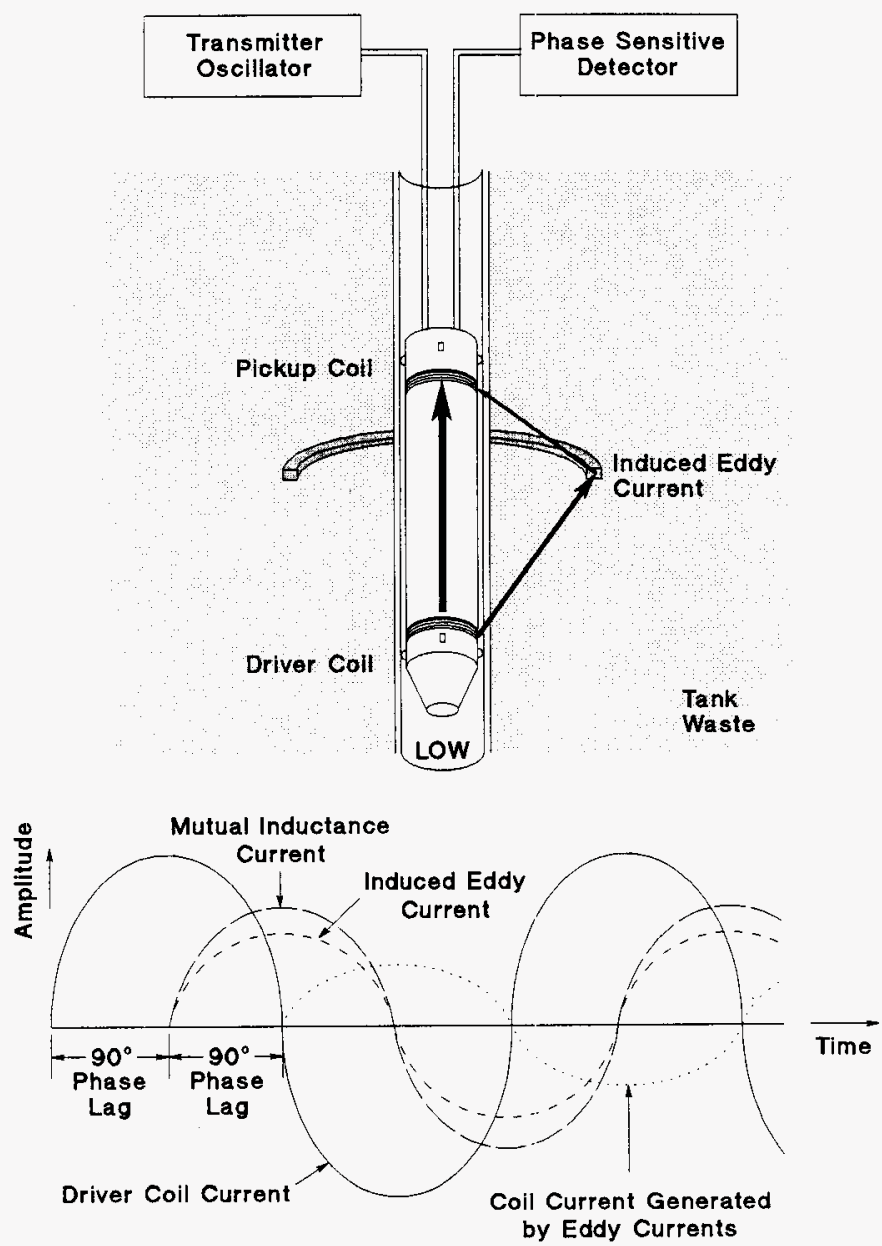
There is some phase shift of the electromagnetic field with distance from the driver and pickup coils. Also, there is additional phase shift with increasing electrical conductivity in the adjacent medium. Because of the low electrical conductivity of the waste, these phase shifts are small secondary effects.

The MIZ-40A eddy current tester is the electromagnetic instrumentation for performing the electrical conductivity measurement and is shown in Figure 2. The EMI measurement is recorded on a removable hard disk in the DDR-1 data recorder, also shown in Figure 2 .

The electromagnetic measurement of electrical conductivity was calibrated in $46 \mathrm{~cm}$ (18 in.) 0.D., $50 \mathrm{~cm}$ (20 in.) high electrical conductivity test stands. The conductivity test stand is shown in Figure 3 . There are four conductivity test stands, $15 \mathrm{mS} / \mathrm{cm}, 50 \mathrm{mS} / \mathrm{cm}, 100 \mathrm{mS} / \mathrm{cm}$, and $150 \mathrm{mS} / \mathrm{cm}$. There is also an empty conductivity stand filled with air. There is a $7.62 \mathrm{~cm}$ (3 in.) I.D. plastic tube in the center for the EMI probe. The electrically conductive medium is water with potassium chloride for the electrolyte. The electrical conductivity was measured with a temperature compensated electrical conductivity meter. The conductivity meter calibration was verified by measurements on a conductivity standard solution.

\subsection{ELECTRICAL CONDUCTIVITY DEPENDENCE ON MOISTURE CONTENT}

The EMI technique measures electrical conductivity. It is important to consider the theoretical basis for the electrical conductivity dependance on moisture content in Hanford high-level waste (HLW) tanks. The gross features of electrical conductivity from pure water to fused salt are depicted in Figure 4.

The electrical conductivity of an aqueous solution from pure water to fused salts can be considered between the following phases:

- Pure water

- Chemically saturated electrolytic solution

- Wet solid with all pores volume filled with liquid

- Moist solid dried to the loss of hydraulic conductivity

- Completely dry fused solids.

The electrical conductivity of pure water is very low and increases as electrolytes are added into solution. The electrical conductivity continues to increase as the electrolyte concentration is increased, but the rate of increase of electrical conductivity diminishes as the concentration increases. At electrolyte saturation, the electrical conductivity is at the maximum. As more salts are added, the proportion of solids increases and the liquid solution becomes an interstitial liquid. The electrical conductivity decreases according to an undefined relationship between the solid and liquid solution. 
Figure 2. EMI Eddy Current Electronic Components.*

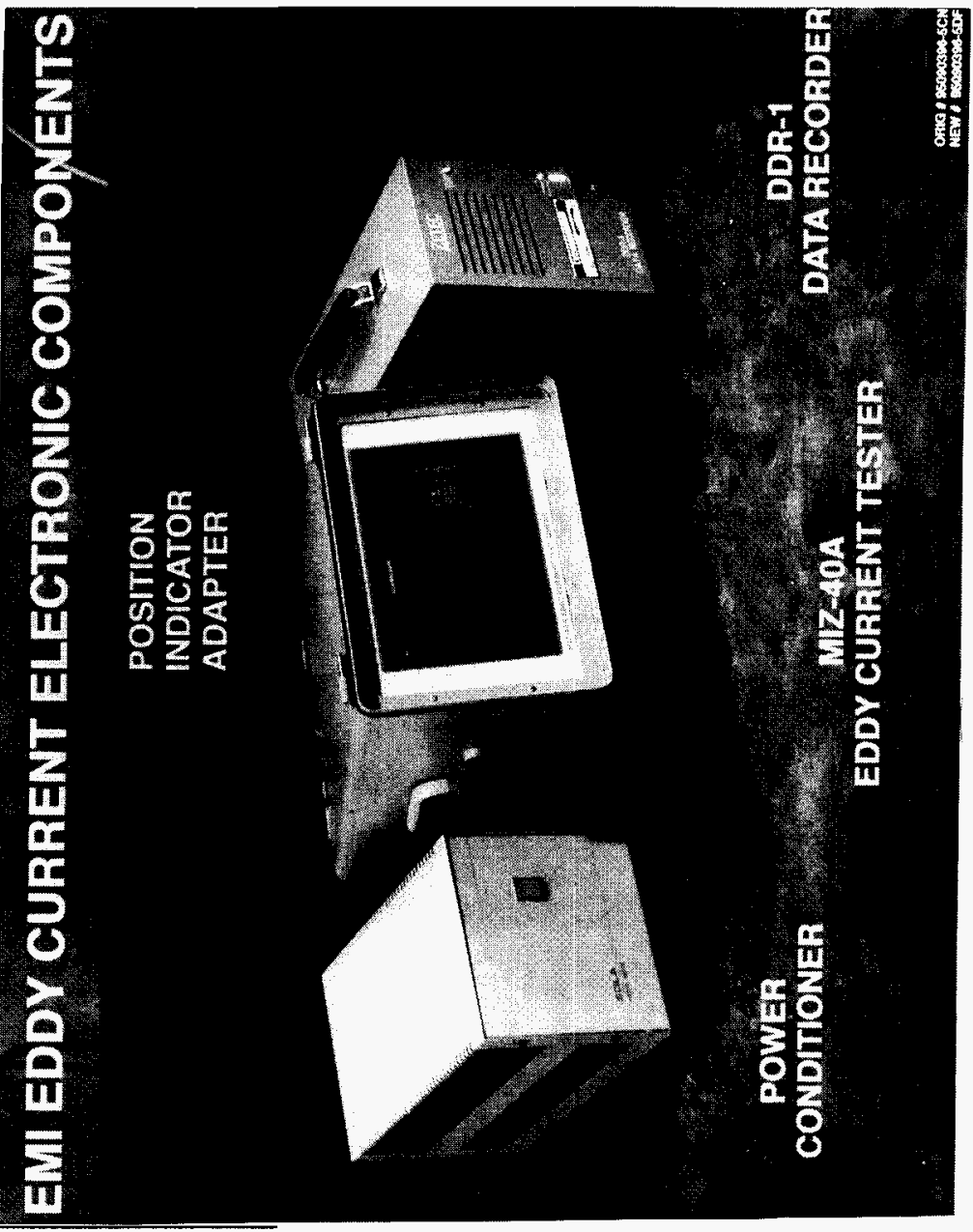

"The MIZ-40A eddy current tester is used to perform the electrical conductivity measurement. The EMI measurement is recorded on a removable hard disk in the DDR-l data recorder. The position indicator adaptor provides a reference signal when the EMI probe is in motion and scanning up or down in the LOW. 
Figure 3. EMI Laboratory Test Stands.*

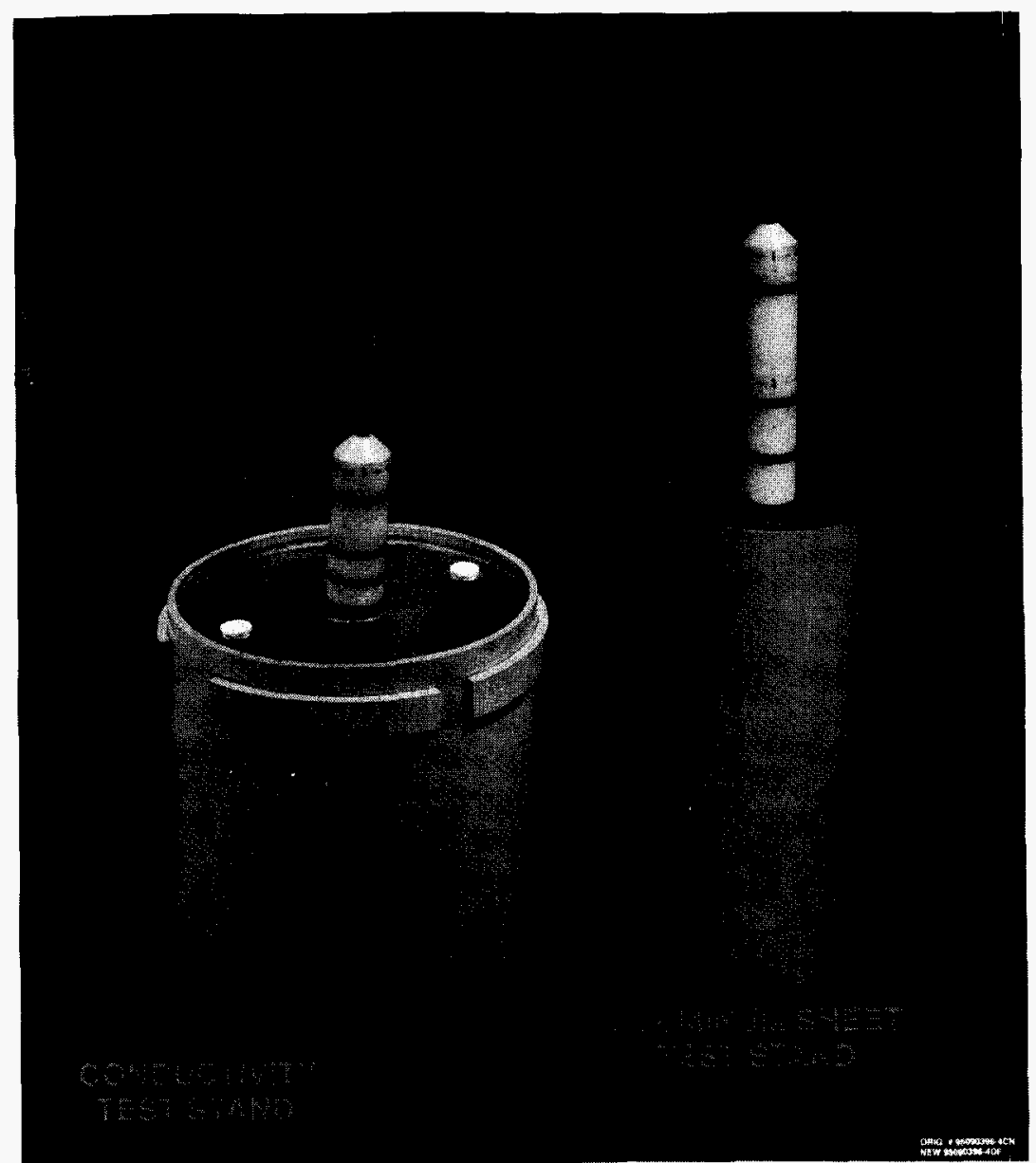

"The conductivity test stands are $50 \mathrm{~cm}(18 \mathrm{in.}) 0 . \mathrm{D}$., and $46 \mathrm{~cm}(20 \mathrm{in.})$ high. There are four conductivity test stands, $15 \mathrm{mS} / \mathrm{cm}, 50 \mathrm{mS} / \mathrm{cm}, 100 \mathrm{mS} / \mathrm{cm}$, and $150 \mathrm{mS} / \mathrm{cm}$. This conductivity range is appropriate and extends above any conductivity measured in a HLW tank. There is a $7.62 \mathrm{~cm}(3$ in.) I.D. plastic tube in the center for the EMI probe. The electrical conductive medium is water with potassium chloride for the electrolyte. 
Figure 4. Electrical Conductivity Between Pure Water and Fused Salt.

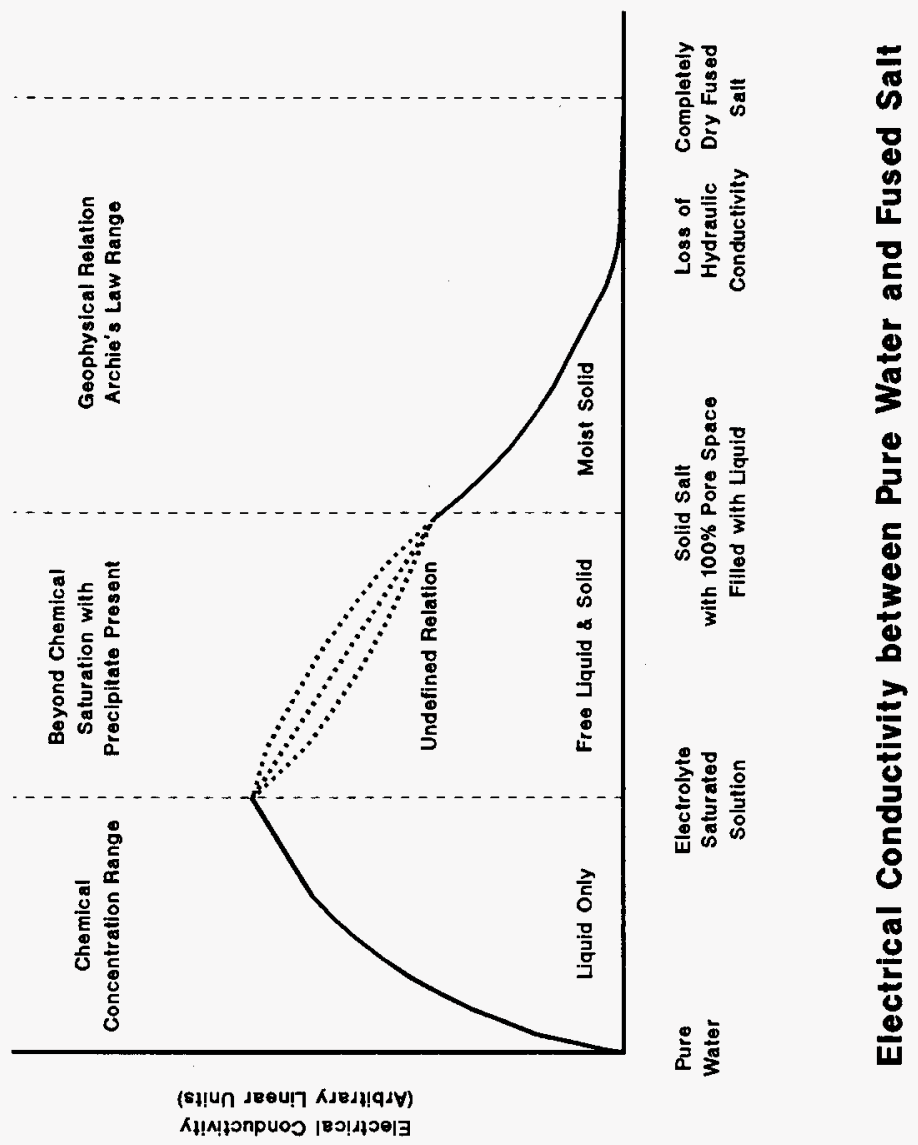


As water is removed from the pore space of the solid salt, the electrical conductivity decreases according to Archie's Law. As porous solid salt is dried there is a loss of hydraulic conductivity, and the electrical conductivity becomes very small. Finally, the electrical conductivity of completely dry fused salt is very low.

The two situations of greatest interest to EMI measurements are the electrical conductivity of electrolytic solutions, and electrolytic solutions in a porous solid matrix. The electrolytic solution is discussed in Section 3.3.1.

\subsubsection{Electrical Conductivity of Electrolytic Solutions}

The electrical conductivity of an electrolytic solution depends on the number of dissociated ions in the solution, their mobility, and the electrica] charges of each of the ians. The number of dissociated ions depends on the solubility of various constituent salts. The larger the number of dissociated ions, the higher the absolute electrical conductivity. But, the specific conductance (the electrical conductivity per ion), decreases steadily with the larger number of ions.

The tank waste liquid contains free charged ions from the dissolved salts. When these ions are subjected to an imposed alternating magnetic field, the cations in the solution are accelerated in one direction and the anions in the other. These directions reverse as the field reverses. The movement of the ions is a current. The movement of the ions encounters viscous drag that limits the velocity of the ions, and determines the ions mobility.

The ionic mobility or conductivity per electrical charge in aqueous solutions is remarkably similar for a wide range of different ions within approximately a factor of 2 , with two notable exceptions, $\mathrm{H}^{+}$and $\mathrm{OH}^{-}$. The limiting ionic conductivity for $\mathrm{H}^{+}$is about seven times greater than most ions, and for $\mathrm{OH}^{-}$it is about four times greater than most ions (see Table 1). The waste in Hanford HLW tanks is caustic, therefore the $\mathrm{H}^{+}$is absent and only the $\mathrm{OH}^{-}$is significant.

Hanford HLW tanks have dominant constituents $\mathrm{NaNO}_{3}, \mathrm{NaNO}_{2}, \mathrm{NaOH}$, and $\mathrm{NaAlO}_{2}$. The chemical proportion varies between HLW tanks. Supernatant may or may not be saturated with electrolytic salts, but the interstitial liquid in the pore spaces of fused salts is most likely a salt saturated solution.

The electrolyte electrical conductivity depends on the mobile ions. The bound water in $\mathrm{Na}_{2} \mathrm{CO}_{3} \cdot 7 \mathrm{H}_{2} \mathrm{O}$ or $\mathrm{Na}_{2} \mathrm{SO}_{4} \cdot 10 \mathrm{H}_{2} \mathrm{O}$ does not add to the mobile ions, and is not measured in the EMI determination of moisture content. This salt-saturated solution electrical conductivity is a primary factor used to calculate liquid volume fraction and free-water weight percent. 
Table 1. Ionic Conductivity for Relevant Ions $\left(25^{\circ} \mathrm{C}\right)$.

\begin{tabular}{|c|c|}
\hline Ion & $\begin{array}{c}\text { Molar conduct ivity } \\
\left(\mathrm{cm}^{2} \mathrm{~S} \mathrm{~mol}^{-1}\right)\end{array}$ \\
\hline $\mathrm{H}^{+}$ & 349.65 \\
\hline $\mathrm{OH}^{-}$ & 198.00 \\
\hline $\mathrm{Na}^{+}$ & 50.08 \\
\hline $\mathrm{NO}_{3}^{-}$ & 71.42 \\
\hline $\mathrm{NO}_{2}^{-}$ & 71.80 \\
\hline $\mathrm{AlO2}^{-}$ & $?$ \\
\hline
\end{tabular}

The electrical conductivity of an electrolytic solution depends on the quantity, charge, and mobility of the dissociated ions in the solution. The number of dissociated ions depends on the quantity of dissolved salts in the liquid. The temperature, solubility of salt, and presence of other salts all influence the number of dissolved ions. For dilute solutions, by increasing the number of dissociated ions linearly increases electrical conductivity of the solution. However, as more salt is dissolved with a corresponding increase in the number of dissociated ions, the interactions between the ions increase and the electrical conductivity is difficult to predict theoretically (Harned and Owen 1950). Because of this difficulty, solutions were created with the same range of dissolved salts as in the tank waste liquids, and the conductivities of these solutions were measured. The results of these measurements were used with the actual waste tank sample data to evaluate the variation of electrical conductivity for waste tank liquids.

The dominant constituents in the waste tank liquid samples are $\mathrm{NaNO}_{3}$, $\mathrm{NaNO}_{2}, \mathrm{NaOH}$, and $\mathrm{NaAlO}_{2}$. The relative chemical proportions of these salts vary between tanks. Supernatant and liquid in the sludge waste may or may not be saturated with electrolytic salts. The interstitial liquid in the pore spaces of saltcake is considered saturated since it was formed from hot saturated liquid slurries.

Two experimental series of tests were designed. The first series had three levels of four components $\left(\mathrm{NaNO}_{3}, \mathrm{NaNO}_{2}, \mathrm{NaOH}\right.$, and $\mathrm{NaAlO}_{2}$ ) with 27 test. solutions covering a range from $2 \mathrm{M}$ to $6 \mathrm{M} \mathrm{NaOH}$. The second series had three levels of three component $\left(\mathrm{NaNO}_{3}, \mathrm{NaNO}_{2}\right.$, and $\left.\mathrm{NaOH}\right)$, with 15 test solutions over the range of $0 \mathrm{M}$ to $2 \mathrm{M} \mathrm{NaOH}$. These two series of experimental tests were necessary because $\mathrm{NaAlO}_{2}$ requires a minimum of $2 \mathrm{M} \mathrm{NaOH}$ to be dissolved. These two series and the levels of components are believed to cover the major components of expected interstitial liquids and supernatant solutions in Hanford waste tanks. The conductivity of the 42 test solutions was measured at temperatures ranging from $20^{\circ} \mathrm{C}$ to $75^{\circ} \mathrm{C}$ to establish the temperature dependant electrical conductivity as a function of chemical composition. 
The temperature data were used to interpolate the conductivity for the different chemical compositions at regular $5{ }^{\circ} \mathrm{C}$ temperature intervals ranging from $20^{\circ} \mathrm{C}$ to $75^{\circ} \mathrm{C}$. Regression coefficients, $a, b_{i}$ and $c_{i, j}$ were calculated for each chemical component in each solution for each $5{ }^{\circ} \mathrm{C}$ "interva1. The electrical conductivity in $\mathrm{mS} / \mathrm{cm}$ was the dependent variable, and the dependent variables were the molarity of the $\mathrm{NaOH}, \mathrm{NaNO}_{3}, \mathrm{NaNO}_{2}$, and $\mathrm{NaAlO}_{2}$. Terms to second order were considered for their statistical significance, and the less significant terms were dropped from the model. These fitted parameters were used to predict the electrical conductivity of the analyzed chemical compositions of the single-shell waste tanks by using the following equation.

$$
\sigma_{w}(T, M)=a+\sum_{i=1}^{4} b(T)_{i} M_{i}+\sum_{i=1}^{4} \sum_{j=1}^{4} c(T)_{i, j} M_{i} M_{j}
$$

where

$$
\begin{aligned}
\sigma_{H} & =\text { Liquid electrical conductivity }(\mathrm{mS} / \mathrm{cm}) \\
T & =\text { Temperature }\left({ }^{\circ} \mathrm{C}\right) \\
M_{i} & =\text { Molarity of } i^{\text {th }} \text { component, i.e. } \mathrm{NaOH}, \mathrm{NaAlO}_{2}, \mathrm{NaNO}_{3} \text {, or } \mathrm{NaNO}_{2} \text { (moles/1) } \\
a & =\text { Constant regression coefficient }(\mathrm{mS} / \mathrm{cm}) \\
b_{i} & =\text { Regression coefficient for } i^{\text {th }} \text { component }(\mathrm{mS} / \mathrm{cm}) /(\mathrm{moles} / 1) \\
c_{i, j} & =\text { Regression coefficient for } i^{\text {th }} \text { times } j^{\text {th }} \text { component }(\mathrm{mS} / \mathrm{cm}) /(\mathrm{moles} / 1)^{2}
\end{aligned}
$$

This high electrical conductivity property of the $\mathrm{OH}^{-}$ion explains the relatively large magnitude for the $\mathrm{NaOH}$ regression coefficient (shown in Table 2). The diminishing efficiency of additional ions to contribute electrical conductivity explains why the $c_{i, i}$ quadratic terms are all negative. The interference of different ions with the mobility of other ions explains why all the $c_{i, j}$ regression coefficients are negative.

\subsubsection{Electrical Conductivity Solution Modeling}

A total of 72 drainable liquid or supernatant solution chemical analyses were reported (Van Vleet 1993a and 1993b), these formed the data base of expected compositions for interstitial liquid which are the source of electrical conductivity in Hanford HLW waste tanks. Eighteen of the 72 solutions were listed as drainable liquids and the remaining 54 were listed as supernatant solutions. 
Table 2. Electrical Conductivity Regression Coefficients.

\begin{tabular}{|c|c|c|c|c|c|c|c|}
\hline \multirow{2}{*}{\multicolumn{2}{|c|}{$M_{i}$ or $M_{i}, M_{j}$}} & \multirow{2}{*}{$\begin{array}{c}\begin{array}{c}\text { Temperature } \\
\text { dependence }\end{array} \\
\mathbf{m}\end{array}$} & \multirow{2}{*}{$\begin{array}{c}\begin{array}{c}\text { Constant } \\
\text { with } \\
\text { temperature }\end{array} \\
\mathrm{b} \\
\end{array}$} & & \multicolumn{3}{|c|}{$\begin{array}{l}\text { Temperature for } \\
\text { regression } \\
\text { coefficients }\end{array}$} \\
\hline & & & & & $25^{\circ} \mathrm{C}$ & $50{ }^{\circ} \mathrm{C}$ & $75^{\circ} \mathrm{C}$ \\
\hline \multicolumn{2}{|c|}{ Constant } & 1.36989 & 74.0167 & $a=$ & 108.26 & 142.51 & 176.76 \\
\hline $\mathrm{NaOH}$ & & 1.907 & 35.1738 & $b_{1}=$ & 82.85 & 130.52 & 178.20 \\
\hline $\mathrm{NaATO}_{2}$ & & 0.51124 & -21.488 & $b_{2}=$ & -8.71 & 4.07 & 16.86 \\
\hline $\mathrm{NaNO}_{3}$ & & 0.84134 & 3.06732 & $b_{3}=$ & 24.10 & 45.13 & 66.17 \\
\hline $\mathrm{NaNO}_{2}$ & & 1.10913 & 15.8596 & $b_{4}=$ & 43.59 & 71.32 & 99.04 \\
\hline $\mathrm{NaOH}$ & $\mathrm{NaAlO}_{2}$ & -0.163 & -1.0865 & $c_{12}=$ & -5.16 & -9.24 & -13.31 \\
\hline $\mathrm{NaOH}$ & $\mathrm{NaNO}_{3}$ & -0.2937 & -6.1382 & $c_{13}=$ & -13.48 & -20.83 & -28.17 \\
\hline $\mathrm{NaAlO}_{2}$ & $\mathrm{NaNO}_{2}$ & -0.7831 & -10.883 & $c_{24}=$ & -30.46 & -50.04 & $-69.6 I$ \\
\hline $\mathrm{NaOH}$ & $\mathrm{NaOH}$ & -0.1382 & -5.4911 & $c_{11}=$ & -8.95 & -12.40 & -15.86 \\
\hline $\mathrm{NaNO}_{3}$ & $\mathrm{NaNO}_{3}$ & -0.1044 & 0.73291 & $c_{33}=$ & -1.88 & -4.49 & -7.09 \\
\hline $\mathrm{NaNO}_{2}$ & $\mathrm{NaNO}_{2}$ & -0.1857 & -4.4752 & $c_{44}=$ & -9.12 & -13.76 & -18.40 \\
\hline
\end{tabular}

The electrical conductivity of the chemical composition of the solutions was calculated at specific temperatures using the regression coefficients previously described. These fitted parameters were used to predict the electrical conductivity of the analyzed chemical compositions of the singleshell waste tanks. The results are listed in Table 3.

Table 3. Predicted Electrical Conductivity of Analyzed Compositions.

\begin{tabular}{|l|c|c|c|}
\hline & $\sigma_{\mathrm{H}}\left(\mathrm{T}=25^{\circ} \mathrm{C}, \mathrm{M}\right)$ & $\sigma_{\mathrm{H}}\left(\mathrm{T}=50^{\circ} \mathrm{C}, \mathrm{M}\right)$ & $\sigma_{\mathrm{H}}\left(\mathrm{T}=75^{\circ} \mathrm{C}, \mathrm{M}\right)$ \\
\hline $\begin{array}{l}\text { Analyzed liquids } \\
\text { (35 samples) }\end{array}$ & $192.30 \pm 26.71$ & $294.48 \pm 49.17$ & $396.65 \pm 72.96$ \\
\hline
\end{tabular}

This calculation infers that the EMI data interpretation would benefit from knowing the temperature distribution and the approximate chemical composition of the HLW tank being scanned. The most important of these two quantities is the waste material temperature, which is also the easiest one to measure. A completely unknown chemical composition could introduce an uncertainty on the order of $\pm 26.71 / 192.30 \times 100 \%$, or approximately $\pm 14 \%$ relative uncertainty at one standard deviation. Of course, any additional 
tank specific facts and information could reduce the effect of this extreme uncertainty of unknown chemical composition. The EMI sensitivity to loss of hydraulic conductivity is not affected by this relative uncertainty of unknown chemical composition or even an unknown temperature.

\subsection{WASTE GEOMETRY DESCRIPTION}

The measured conductivity of tank waste varies with the following:

- Water content. The amount of water in the waste is limited by the porosity, which is the amount of void space in the waste solid

- Waste liquid salinity. The type and quantity of dissolved salts in the waste liquid

- Waste geometry. The distribution of the water in the waste is determined by the size, shape, and interconnections of the void spaces

- Waste temperature. Increasing temperature increases the waste conductivity.

The moisture content of the waste is calculated from the waste composition using the following equation:

$$
M C=\frac{\theta S_{\mathrm{H}} \rho_{\mathrm{L}}\left[\frac{\rho_{\mathrm{H}_{2} \mathrm{O}}}{\rho_{\mathrm{L}}}\right]}{(1-\theta) \rho_{\mathrm{S}}+\theta S_{\mathrm{H}} \rho_{\mathrm{L}}}
$$

where

$$
\begin{array}{ll}
\mathrm{MC} & =\text { moisture content (wt\%) } \\
\theta & =\text { porosity (fraction) } \\
\mathrm{S}_{\mathrm{W}} & =\text { water saturation (fraction) } \\
\rho_{\mathrm{L}} & =\text { waste } 1 \text { iquid density }\left(\mathrm{g} / \mathrm{cm}^{3}\right) \\
{\left[\frac{\rho_{\mathrm{H}_{2} \mathrm{O}}}{\rho_{\mathrm{L}}}\right]} & =\text { water in waste liquid }(\mathrm{fraction}) \\
\rho_{\mathrm{S}} & =\text { waste solid density }\left(\mathrm{g} / \mathrm{cm}^{3}\right)
\end{array}
$$


The free-water moisture content is the free-water weight divided by the combined liquid and solid weights in the porous medium. The bound water is included in the solid weight.

Based on the evaluation of the geophysics description of different types of rock formations, the tank waste is being regarded as consolidated sediment where the porosity is the space left over between grains of solid matter.

Pore spaces must be interconnected and at least partially filled with water in order for the waste to effectively conduct electricity. The pore volumes consist of two parts; larger voids called storage pores, and smaller connecting pores. Most of the resistance to electrical current is provided by the connecting pores. The higher the ratio of the volume of connecting pores to storage pores the greater the relative conductivity of the waste (Wait 1971).

A great deal of research has been done to correlate resistivity directly with water content for petroleum bearing rocks. It has been observed that the resistivity varies as the inverse square of the porosity, when the rock is fully saturated with water. This has led to the wide spread use of an empirical formula relating resistivity and porosity know as Archie's Law. Archie's Law when expressed in terms of conductivity, the inverse of resistivity has the following form:

$$
\sigma_{t}=\sigma_{\mathrm{w}} \frac{\theta^{m}}{a}
$$

where

$\sigma_{t}=$ bulk electrical conductivity of waste with pores filled

$\sigma_{w}=$ electrical conductivity of liquid contained in pore structure

$\theta=$ porosity expressed as a fraction of the volume of the waste

$a, m=$ empirical constants based on experimental observations

This is the basic equation of we11-log interpretation. The well-logging industry recognizes and has its origin in this equation (Dewan 1983).

Geologists have made a large number of measurements of both the porosity and resistivity in order to determine values for a and $m$ with a good degree of reliability. Measurements data are typically scattered wide because of the variability of the structure between samples. The sample measurements have been separated into groups based on the porosity. Average values for parameters a and $m$ for three groups of sedimentary rocks (Wait 1971) are listed in Table 4. 
Table 4. Forms of Archie's Law for Some Sedimentary Rocks.

\begin{tabular}{|l|c|c|c|}
\hline \multicolumn{1}{|c|}{ Description of rock } & Porosity & $a$ & $m$ \\
\hline $\begin{array}{l}\text { Weakly-cemented detrital rocks, such as sand, } \\
\text { sandstone, and some limestones }\end{array}$ & $25 \%$ to $45 \%$ & 0.88 & 1.37 \\
\hline $\begin{array}{l}\text { Moderately well-cemented sedimentary rocks, } \\
\text { including sandstones and limestones }\end{array}$ & $18 \%$ to $35 \%$ & 0.62 & 1.72 \\
\hline Firmly-cemented sedimentary rocks & $5 \%$ to $25 \%$ & 0.62 & 1.95 \\
\hline
\end{tabular}

$a, m=$ empirical constants in: $\sigma_{t}=\sigma_{w} \theta^{m} / a$.

The tank waste is assumed to be similar to detrital rocks formed grains accumulated as sediment from suspension. In this type of rock, the a has a value of 0.88 and $m$ has a value of 1.37 . This choice of values for both a and $m$ is a best estimate.

The conductance of waste that is partially saturated with liquid is less than the conductance of the same amount of waste that is fully saturated with water. If part of the pore space in the waste is occupied by nonconducting fluid (organic) or gas, the water saturation, $S_{w}$, is less than 1 and the waste conductance decreases. Near the surface of the waste, part of the pore space may be filled with air. Studies of the effect of desaturation on the conductance of various types of rock formations have led to an empirical expression resembling Archie's Law.

$$
\sigma_{t}\left(S_{w} \leq 1\right)=\sigma_{t}\left(S_{w}=1\right) S_{w}^{n_{1}}
$$

where

$\sigma_{t}\left(S_{w} \leq 1\right)=$ conductance of partly dry medium

$\sigma_{t}\left(S_{w}=1\right)=$ conductance with all pore spaces filled

$\mathrm{S}_{\mathrm{w}} \quad=$ desaturation (pore fraction water filled)

$n_{1}=2$, a constant (Wait 1971)

There is general acceptance for the value $n_{1}=2$ (Wait 1971, Dewan 1983, Serra 1984, Hearst and Nelson 1985), it is commonly used throughout the well-logging industry. 


\subsection{EMI CALCULATED MOISTURE CONTENT}

$$
M C=\frac{\rho_{\mathrm{L}}}{\rho_{\mathrm{b}}}\left[\frac{\rho_{\mathrm{H}_{2} \mathrm{O}}}{\rho_{\mathrm{L}}}\right] \theta S_{\mathrm{w}}^{\mathrm{n}_{1}}
$$

where

MC = fraction by mass of water in the waste

$\rho_{L}=$ density of the interstitial 1 iquid $\left(\mathrm{g} / \mathrm{cm}^{3}\right)$

$\rho_{\mathrm{b}}=$ bulk density of the waste $\left(\mathrm{g} / \mathrm{cm}^{3}\right)$

$\left(\frac{\rho_{\mathrm{H}_{2} \mathrm{O}}}{\rho_{L}}\right)=$ water mass fraction in interstitial liquid

$\theta=$ porosity, connected pore space to total volume

$\mathrm{S}_{\mathrm{W}} \quad=$ fraction total pore space filled with liquid

$n_{1}=2$, a constant (Wait 1971)

The EMI measurement of electrical conductivity is converted to moisture content by using Archie's Law which has served the wel1-logging industry since the 1940's. The applicability of Archie's Law depends on the interstitial liquid being electrically conductive and the porous solid that is not being electrically conductive. Archie's Law has been extended to electricaliy conductive solids (de Witte 1950).

The calibration of the measured electrical conductivity to moisture content determination depends on the following:

- HLW porosity (absolute porosity, not drainable porosity)

- HLW interstitial liquid electrical conductivity

- HLW solid (salt grain particle) density

- $\mathrm{HLW}$ interstitial 1 iquid density, and water fraction (fraction of $\mathrm{H}_{2} \mathrm{O}$ in salt-saturated liquid).

The calculated effect because of the expected uncertainties for each of these physical properties will be considered in separate sections. 
The free-water moisture content is the free-water weight divided by the combined liquid and solid weights in the porous medium. The bound water is included in the solid weight.

$$
\mathrm{MC}=\frac{\theta \mathrm{S}_{\mathrm{W}} \rho_{\mathrm{L}}\left[\frac{\rho_{\mathrm{H}_{2} \mathrm{O}}}{\rho_{\mathrm{L}}}\right)}{(1-\theta) \rho_{\mathrm{S}}+\theta \mathrm{S}_{\mathrm{H}} \rho_{\mathrm{L}}}
$$

where

MC = moisture content mass fraction of free-water in porous medium

$\theta \quad=$ absolute porosity volume fraction

$S_{W} \quad=$ volume fraction of the pore volume occupied by interstitial liquid

$\rho_{\mathrm{L}} \quad=$ interstitial liquid density

$\left[\frac{\rho_{\mathrm{H}_{2} \mathrm{O}}}{\rho_{\mathrm{L}}}\right]=$ water mass fraction in interstitial Tiquid

$\rho_{s} \quad=$ solid (salt grain particle) density.

The matrix electrical conductivity is described by the following equation:

$$
\sigma_{t}\left(\sigma_{w}, \theta, S_{w}\right)=\frac{\sigma_{w} \theta^{m}}{a}\left(S_{w}\right)^{n_{q}}
$$

where

$\sigma_{t}=$ bulk electrical conductivity of the porous solid liquid matrix

$\theta S_{W}=$ liquid volume fraction

$\theta=$ porosity, volume fraction of solid matrix

$\sigma_{w}=$ electrical conductivity of interstitial liquid in porous medium

$a=0.88$, a constant parameter from Archie's Law

$m=1.37$, a constant parameter from Archie's Law

$n_{1}=2.0$, a constant parameter from Archie's Law. 
The determination of moisture content is based on the best available data, values for $\sigma_{y}$, the interstitial liquid electrical conductivity, $\theta$, the porosity, $S_{H}$, and the liquid filled pore space volume fraction. The $\sigma_{H}(T, M)$ depends on temperature and composition. The temperature is usually already measured, and there has been a lot of work done on temperature distribution in Hanford waste tanks. The porosity $\theta$, can be estimated from previous measurements, or determinations in similar waste tanks. The $S_{4}$ parameter is believed to be the most likely to vary vertically along a liquid observation well (LOW). For this reason, the $S_{w}$ parameter is calculated from the EMI electrical conductivity measurement.

$$
S_{w}=\left[\frac{a\left(\sigma_{t} / \sigma_{w}(T, M)\right)}{\theta^{m}}\right]^{1 / n_{1}} \quad\left(0 \leq S_{w} \leq 1\right)
$$

Substituting this determined liquid occupied pore volume into the moisture content, the equation shows

$$
M C=\frac{\left.\theta\left[\frac{a \sigma_{t} / \sigma_{w}(T, M)}{\theta^{m}}\right]^{1 / n_{1}} \rho_{L} \int \frac{\rho_{\mathrm{H}_{2} \mathrm{O}}}{\rho_{\mathrm{L}}}\right]}{(1-\theta) \rho_{S}+\theta\left[\frac{\mathrm{a} \sigma_{t} / \sigma_{\mathrm{H}}(\mathrm{T}, \mathrm{M})}{\theta^{\mathrm{m}}}\right)^{1 / \mathrm{n}_{1}} \rho_{\mathrm{L}}}
$$

where

$$
\begin{aligned}
& \text { MC = moisture content, calculated mass fraction of free-water in } \\
& \text { porous medium } \\
& \theta=\text { porosity, } 0.50 \text { with uncertainty of }+0.05 \\
& \sigma_{\mathrm{t}} \quad=\text { EMI measured electrical conductivity of the moist solid matrix, } \\
& \text { this may be } 80,60,40,20,10 \text {, or } 5 \mathrm{mS} / \mathrm{cm} \\
& \text { a } \quad=0.88 \text {, a constant parameter from Archie's Law } \\
& \sigma_{H}(T, M)=\text { interstitial liquid electrical conductivity, this is a function } \\
& \text { of } T \text { (temperature), and } M \text { (chemical composition), and is assumed } \\
& \text { to be } 200 \mathrm{mS} / \mathrm{cm} \text { with uncertainty of } \pm 25 \mathrm{mS} / \mathrm{cm} \\
& \mathrm{m} \quad=1.37 \text {, a constant parameter from Archie's Law } \\
& n_{1}=2.0 \text {, a constant parameter from Archie's Law } \\
& \rho_{\mathrm{L}} \quad=\text { interstitial liquid density, a function of } M \text { (chemica) } \\
& \text { composition), } 1.177432 \mathrm{~g} / \mathrm{cm}^{3} \text { with an uncertainty } \\
& \text { of } \pm 0.094255 \mathrm{~g} / \mathrm{cm}^{3}
\end{aligned}
$$


$\rho_{\mathrm{H} 2 \mathrm{O}} / \rho_{\mathrm{L}}=$ interstitial liquid water fraction, 0.792408 with an uncertainty of \pm 0.109754

$\rho_{\mathrm{S}} \quad=$ solid particle density, this is a function of $M$ (chemica) composition), $2.20 \mathrm{~g} / \mathrm{cm}^{3}$ with an uncertainty of $\pm 0.10 \mathrm{~g} / \mathrm{cm}^{3}$

This equation is used to determine moisture content from EMI measured electrical conductivity in moist saltcake media.

\subsection{POROSITY EFFECT}

The porosity involved in the determination of moisture content is the total porosity, not simply the drainable liquid porosity. Porosity in Hanford waste tanks has been a concern. A range of porosities was observed and an average $35 \%$ porosity for liquids that could be pumped was declared (DeWeese 1988). The estimated drainable volume for porosity underestimates the absolute porosity that is needed for EMI moisture content calculations. The porosity for drainable liquids represents a definite lower limit for absolute porosity.

Simmons (1995) stated that absolute porosity of 40 vol\% to 60 vol\% could be accepted for various saltcake profiles. Computer calculations for waste tank vertical moisture profiles (Simmons 1995, Table 1, p. 23) used 0.50 absolute porosity, although in 3 out of 22 cases the absolute porosity had to be increased to 0.55 or 0.60 . This is the basis for assuming a 0.50 porosity with an estimated uncertainty of one standard deviation of +0.05 . The uncertainty range considered is from 0.50 to 0.55 .

This physical property has effect on the calculated moisture content, because of the exponent, $m=1.37$. The effect of porosity was calculated by assuming a range of porosity values over a wide range of possible values. The moisture weight percent effect of this porosity uncertainty can be determined from Table 5 .

Table 5. Porosity Effect on EMI Inferred Moisture Content.

\begin{tabular}{|c|c|c|c|c|c|}
\hline \multicolumn{6}{|c|}{$\begin{array}{c}\text { Calculated Moisture Content from EMI Matrix Electricat } \\
\text { Conductivity as a Function of Porosity }\end{array}$} \\
\hline & \multicolumn{5}{|c|}{ Porosity } \\
\hline $\begin{array}{c}\text { Matrix electrical } \\
\text { conductivity mS/cm }\end{array}$ & 0.40 & 0.45 & 0.50 & 0.55 & 0.60 \\
\hline 100 & & & & & 0.3411 \\
\hline 80 & & & 0.2678 & 0.2923 & 0.3196 \\
\hline 60 & 0.2026 & 0.2218 & 0.2429 & 0.2663 & 0.2926 \\
\hline 40 & 0.1735 & 0.1909 & 0.2102 & 0.2317 & 0.2562 \\
\hline 20 & 0.1311 & 0.1453 & 0.1611 & 0.1792 & 0.2001 \\
\hline 10 & 0.0974 & 0.1085 & 0.1212 & 0.1357 & 0.1528 \\
\hline 5 & 0.0715 & 0.0800 & 0.0897 & 0.1010 & 0.1145 \\
\hline
\end{tabular}


For $80,60,40,20,10$, and $5 \mathrm{mS} / \mathrm{cm}$, the +0.05 porosity uncertainty on a believed absolute porosity of 0.50 is calculated to be $2.45,2.34,2.15,1.81$, 1.45 , and $1.13 \mathrm{wt} \% \mathrm{H}_{2} \mathrm{O}$ content respectively.

\subsection{INTERSTITIAL LIQUID CONDUCTIVITY EFFECT}

The interstitial liquid electrical conductivity in the determination of moisture content is $\sigma_{w}(T, M)$ and depends on temperature and composition. The temperature is usually already measured, and there has been a lot of work done on temperature distribution in Hanford waste tanks. This liquid electrical conductivity physical property can be bounded from temperature measurements and HLW chemical analysis values. From the previous section (Section 3.3.2) on electrical conductivity solution modeling, the calculated electrical conductivity of 35 analyzed waste tank solution was $192.30 \pm 26.71 \mathrm{mS} / \mathrm{cm}$ $\left(25^{\circ} \mathrm{C}\right)$. For this reason, the liquid electrical conductivity was assumed to be $200 \mathrm{mS} / \mathrm{cm}$ with an uncertainty of $\pm 25 \mathrm{mS} / \mathrm{cm}$ for the purpose of these calculations. The results of the calculations performed are shown in Table 6 .

Table 6. Liquid Electrical Conductivity Effect on EMI Moisture Content.

\begin{tabular}{|c|c|c|c|c|c|}
\hline \multicolumn{2}{|c|}{$\begin{array}{c}\text { Calculated Moisture Content from EMI Matrix Electrical Conductivity } \\
\text { as a Function of Liquid Electrical } \\
\text { Conductivity }\end{array}$} \\
\hline & \multicolumn{4}{|c|}{ Liquid electrical conductivity $\mathrm{mS} / \mathrm{cm}$} \\
\hline $\begin{array}{c}\text { Matrix electrical } \\
\text { conductivity mS/cm }\end{array}$ & 150 & 175 & 200 & 225 & 250 \\
\hline 100 & & & & & 0.2678 \\
\hline 80 & & & 0.2678 & 0.2575 & 0.2484 \\
\hline 60 & 0.2678 & 0.2543 & 0.2429 & 0.2331 & 0.2245 \\
\hline 40 & 0.2331 & 0.2206 & 0.2102 & 0.2012 & 0.1934 \\
\hline 20 & 0.1804 & 0.1699 & 0.1611 & 0.1537 & 0.1473 \\
\hline 10 & 0.1367 & 0.1282 & 0.1212 & 0.1152 & 0.1101 \\
\hline 5 & 0.1018 & 0.0951 & 0.0897 & 0.0851 & 0.0812 \\
\hline
\end{tabular}

For $80,60,40$, and $20 \mathrm{mS} / \mathrm{cm}$, a $\pm 25 \mathrm{mS} / \mathrm{cm}$ uncertainty on a believed liquid electrical conductivity of $200 \mathrm{mS} / \mathrm{cm}$ is calculated to be $2.06,2.12$, $1.94,1.62,1.30$, and $1.00 \mathrm{wt} \% \mathrm{H}_{2} \mathrm{O}$ content respectively. 


\subsection{SOLID PARTICLE DENSITY EFFECT}

The solid density $\rho_{\mathrm{s}}$, can be estimated from single crystal densities of the major constituents of Hanford HLW depicted in Table 7 . The major constituents of Hanford's HLW are the four component aqueous mixtures of $\mathrm{NaNO}_{3}, \mathrm{NaNO}_{2}, \mathrm{NaOH}$, and $\mathrm{NaAlO}_{2}$. These major components indicate that the salt grain particle density can be expected to be close to $2.200 \mathrm{~g} / \mathrm{cm}^{3}$ with an uncertainty of $\pm 0.100 \mathrm{~g} / \mathrm{cm}^{3}$.

Table 7. Solid Density of HLW Components (Weast 1976).

\begin{tabular}{|c|c|}
\hline \multicolumn{2}{|c|}{$\begin{array}{l}\text { A. Solid Density of Major } \mathrm{HLW} \\
\text { Components Density in } \mathrm{g} / \mathrm{cm}^{3} \text {. }\end{array}$} \\
\hline $\mathrm{NaNO}_{3}$ & 2.261 \\
\hline $\mathrm{NaNO}_{2}$ & 2.168 \\
\hline $\mathrm{NaOH}$ & 2.130 \\
\hline $\mathrm{NaAlO}_{2}$ & 1.58 \\
\hline $\mathrm{Al}(\mathrm{OH})_{3}$ & 2.42 \\
\hline \multicolumn{2}{|c|}{$\begin{array}{l}\text { B. Solid Density of Minor } \mathrm{HIW} \\
\text { Components Density in } \mathrm{g} / \mathrm{cm}^{3} \text {. }\end{array}$} \\
\hline $\mathrm{Na}_{3} \mathrm{C}_{6} \mathrm{H}_{5} \mathrm{O}_{7}-5 \mathrm{H}_{2} \mathrm{O}$ & 1.857 \\
\hline $\mathrm{Na}_{2} \mathrm{CO}_{3}$ & 2.532 \\
\hline $\mathrm{Na}_{2} \mathrm{CO}_{3}-\mathrm{H}_{2} \mathrm{O}$ & 2.25 \\
\hline $\mathrm{Na}_{2} \mathrm{CO}_{3}-7 \mathrm{H}_{2} \mathrm{O}$ & 1.51 \\
\hline $\mathrm{Na}_{2} \mathrm{CO}_{3}-10 \mathrm{H}_{2} \mathrm{O}$ & 1.44 \\
\hline $\mathrm{Na}_{3} \mathrm{PO}_{4}-10 \mathrm{H}_{2} \mathrm{O}$ & 2.536 \\
\hline $\mathrm{Na}_{3} \mathrm{PO}_{4}-12 \mathrm{H}_{2} \mathrm{O}$ & 1.62 \\
\hline $\mathrm{Na}_{2} \mathrm{SO}_{4}$ & 2.68 \\
\hline $\mathrm{Na}_{2} \mathrm{SO}_{4}-10 \mathrm{H}_{2} \mathrm{O}$ & 1.464 \\
\hline
\end{tabular}

The uncertainty in solid particle density can be converted into uncertainty in calculated moisture weight percent from calculated results contained in Table 8 .

For $80,60,40,20,10$, and $5 \mathrm{mS} / \mathrm{cm}$, the $\pm 0.100 \mathrm{~g} / \mathrm{cm}^{3}$ solid particle density uncertainty on a believed solid particle density of $2.20 \mathrm{~g} / \mathrm{cm}^{3}$ is calculated to be $1.61,1.53,1.40,1.17,0.93$, and 0.72 wt\% $\mathrm{H}_{2} 0$ content respectively. 
Table 8. Solid Density Effect on EMI Inferred Moisture Content.

Calculated Moisture Content from

EMI Matrix Electrical Conductivity as a

Function of Solid Salt Particle Density

\begin{tabular}{|c|c|c|c|c|c|}
\hline \multirow{2}{*}{$\begin{array}{c}\text { Matrix electrical } \\
\text { conductivity } \mathrm{mS} / \mathrm{cm}\end{array}$} & \multicolumn{5}{|c|}{ Sol id density $\mathrm{g} / \mathrm{cm}^{3}$} \\
\cline { 2 - 6 } & 1.90 & 2.00 & 2.10 & 2.20 & 2.30 \\
\hline 100 & & & & & \\
\hline 80 & 0.2944 & 0.2850 & 0.2761 & 0.2678 & 0.2600 \\
\hline 60 & 0.2683 & 0.2593 & 0.2508 & 0.2429 & 0.2355 \\
\hline 40 & 0.2336 & 0.2252 & 0.2174 & 0.2102 & 0.2034 \\
\hline 20 & 0.1808 & 0.1737 & 0.1672 & 0.1611 & 0.1555 \\
\hline 10 & 0.1370 & 0.1313 & 0.1260 & 0.1212 & 0.1167 \\
\hline 5 & 0.1020 & 0.0975 & 0.0934 & 0.0897 & 0.0862 \\
\hline
\end{tabular}

\subsection{INTERSTITIAL LIQUID DENSITY AND WATER FRACTION EFFECT}

Basically, the interstitial liquid density was calculated by averaging 35 measured $H L W$ liquid solutions. The assumed uncertainty was the standard deviation of these 35 measured solutions. Densities may be calculated from the components according to experimental regression coefficients (Reynolds ard Herting 1984), or according to a theoretical mixing rule calculation (Patwardhan and Kumar 1986a, 1986b, and 1993, and Sohnel and Novotny 1985). Both approaches give reasonably consistent results, but the theoretical calculation is more accurate and has less scatter in the calculated densities. The four component aqueous mixtures of $\mathrm{NaNO}_{3}, \mathrm{NaNO}_{2}, \mathrm{NaOH}, \mathrm{NaAlO}_{2}$ were used, and the mixing rule mathematical relationships were used to calculate the solution density. These density calculations are provided in Appendix $C$.

Based on solutions analyzed in $35 \mathrm{HLW}$ tanks the average solution density with one standard deviation calculated according to the aqueous solution mixing rule is:

Density $_{\text {Analyzed solutions }}\left(\rho_{\mathrm{L}}\right)=1.177432 \pm 0.094255 \mathrm{~g} / \mathrm{cm}^{3}$

The water fraction of these analyzed solutions is calculated to be to:

$\mathrm{H}_{2} \mathrm{O}$ Fraction $\left(\rho_{\mathrm{H} 2 \mathrm{O}} / \rho_{\mathrm{L}}\right)=0.792408 \pm 0.109754$ 
The conclusion is that the saturated liquid density for interstitial liquids is $1.177432 \pm 0.094255 \mathrm{~g} / \mathrm{cm}^{3}$. This is the average measured density of HLW tank drainable liquids. The expected water fraction for these measured liquids is $0.792408 \pm 0.109754$. The results of the calculations performed are shown in Table 9.

Assuming that the interstitial liquid is a saturated solution, these uncertainties would be reduced.

Table 9. Liquid Density Effects on EMI Inferred Moisture Content.

\begin{tabular}{|c|c|c|c|c|c|}
\hline \multicolumn{6}{|c|}{$\begin{array}{c}\text { Calculated Moisture Content from } \\
\text { Matrix Electrical Conductivity as a } \\
\text { Function of Interstitial Liquid Density and } \\
\text { Water Fraction of Interstitial Liquid }\end{array}$} \\
\hline \multirow{2}{*}{$\begin{array}{c}\text { Matrix electrical } \\
\text { conductivity mS/cm }\end{array}$} & \multicolumn{4}{|c|}{ Liquid density g/cm ${ }^{3}$, water fraction } \\
\cline { 2 - 6 } & $\begin{array}{c}1.08, \\
0.902\end{array}$ & $\begin{array}{l}1.13, \\
0.847\end{array}$ & $\begin{array}{l}1.18, \\
0.792\end{array}$ & $\begin{array}{l}1.22, \\
0.738\end{array}$ & $1.27,0.682$ \\
\hline 100 & & & & & \\
\hline 80 & 0.2883 & 0.2787 & 0.2678 & 0.2558 & 0.2426 \\
\hline 60 & 0.2608 & 0.2525 & 0.2429 & 0.2323 & 0.2206 \\
\hline 40 & 0.2249 & 0.2180 & 0.2102 & 0.2013 & 0.1915 \\
\hline 20 & 0.1716 & 0.1668 & 0.1611 & 0.1547 & 0.1475 \\
\hline 10 & 0.1285 & 0.1251 & 0.1212 & 0.1166 & 0.1114 \\
\hline 5 & 0.0948 & 0.0925 & 0.0897 & 0.0864 & 0.0827 \\
\hline
\end{tabular}

For $80,60,40$ and $20 \mathrm{mS} / \mathrm{cm}$, the $\pm 0.094255 \mathrm{~g} / \mathrm{cm}^{3}$ saturated liquid density uncertainty on a liquid density of $1.177432 \mathrm{~g} / \mathrm{cm}^{3}$ and the consequent effect on the 1 iquid water fraction is calculated to be $4.57,4.02,3.34$, $2.41,1.71$, and 1.21 wt $\% \mathrm{H}_{2} \mathrm{O}$ content respectively.

\subsection{ARCHIE'S LAW PARAMETER VALUES EFFECT}

The question of using geological Archie's Law parameters and the introduction of bias is shown to be smaller than other known uncertainties, and need not be considered further at this time.

Besides being the standard correlation used in the search for oil, the Archie's Law relationship has been applied to marine sediments (Tromp et. al. 1995), and ground water reservoirs (Yadav 1995), and provided the best correlation to measured data for the East Antarctic ice sheet

(Shabtaie and Bentley 1995). The basic requirements for the valid application of Archie's Law is that the interstitial liquid is electrically conducting and 
the porous solid is relatively non electrically conducting. When examining salt cakes in Hanford HLW tanks, both of these requirement are easily fulfilled.

There is scatter in the reported values for constants $a, m$, and $n_{1}$. The values assumed were selected after consideration of a number of sources. Variation of the Archie's Law parameters does not have as much effect on the calculated moisture content as the other uncertainties. Much effort over a long period of time has been expended to provide a theoretical basis for Archie's Law and the Archie's Law parameters (Wyllie and Gregory 1953).

There is experimental and theoretical data supporting (Wong et. al. 1984) $a=1$ and $m=1.5$ for high porosity, material, $m=2$ for lower porosity material with the transition occurring between 0.2 to 0.4 porosity.

The constants $a$ and $m$ in $\sigma_{t}=\sigma_{m} \sigma^{m} / a$ and their effect on the ratio $\sigma_{t} / \sigma_{w}$, can be calculated. Between the case $a=0.88, m=1.37$ and the case of $a=1.0, m=1.5$. There is a proportional ity when $\theta=0.5$, of $\left(0.5^{1.37} / 0.88\right)$ / $\left(0.5^{1.5} / 1\right)=1.2435$. This looks like a big discrepancy, but consider the final effect on calculated wt\% moisture based on an EMI measurement. The equation used is

$$
\sigma_{t}\left(\sigma_{w}, \theta, S_{w}\right)=\frac{\sigma_{w} \theta^{m}}{a}\left(S_{w}\right)^{n_{1}} \quad\left(0 \leq S_{w} \leq 1\right)
$$

where

$\sigma_{t}=$ bulk electrical conductivity of the porous solid liquid matrix

$\sigma_{n}=$ conductivity of the electrolytic liquid in the porous volume

$\theta=$ porosity expressed as a fraction per unit volume of the solid matrix

$S_{w}=$ fraction of pore space filled with water

$n_{1}=2$, a constant (Wait 1971)

a, $m$ = empirical constants based on experimental observations.

The constant $n_{1}$ has been reported as having a value close to 2 , therefore, $n_{1}=2$ was used. As shown in Table 10, the effect on calculated moisture content is calculated using the same formula that was used to propagate the uncertainties in the final result.

For 60,40 and 20,10 and $5 \mathrm{mS} / \mathrm{cm}$, the change from $\mathrm{a}=0.88, \mathrm{~m}=1.37$ to $\mathrm{a}=\mathrm{l}$, $m=1.5$, has the effect on water fraction is calculated to be $1.88,1.72,1.45$, 1.16 , and 0.90 wt $\% \mathrm{H}_{2} \mathrm{O}$ content respectively. 
Table 10. Archie's Law Parameters Effect on EMI Inferred Moisture Content.

\begin{tabular}{|c|c|c|c|c|c|}
\hline \multicolumn{6}{|c|}{$\begin{array}{l}\text { Calculated Moisture Content from EMI Matrix Electrical } \\
\text { Conductivity as a Function of Archie's Law Parameters }\end{array}$} \\
\hline \multirow{2}{*}{$\begin{array}{l}\text { Matrix electrical } \\
\text { conductivity } \mathrm{mS} / \mathrm{cm}\end{array}$} & \multicolumn{5}{|c|}{ Archie's Law parameters } \\
\hline & $\begin{array}{l}a=0.88 \\
m=1.37\end{array}$ & $\begin{array}{c}a=0.91 \\
m= \\
1.4025\end{array}$ & $\begin{array}{c}a=0.94 \\
m= \\
1.4350\end{array}$ & $\begin{array}{c}a=0.97 \\
m= \\
1.4675\end{array}$ & $\begin{array}{l}a=1.0 \\
m=1.50\end{array}$ \\
\hline \multicolumn{6}{|l|}{100} \\
\hline 80 & 0.2678 & 0.2728 & & & \\
\hline 60 & 0.2429 & 0.2477 & 0.2524 & 0.2570 & 0.2617 \\
\hline 40 & 0.2102 & 0.2145 & 0.2189 & 0.2232 & 0.2274 \\
\hline 20 & 0.1611 & 0.1648 & 0.1684 & 0.1720 & 0.1756 \\
\hline 10 & 0.1212 & 0.1241 & 0.1270 & 0.1299 & 0.1328 \\
\hline 5 & 0.0897 & 0.0919 & 0.0942 & 0.0965 & 0.0987 \\
\hline
\end{tabular}

a, $m=$ empirical constants in: $\sigma_{t}=\sigma_{w} \theta^{m} / a$.

This expected bias because of accepted Archie's Law parameters, a and m, is less than the uncertainties due to different effects on the final calculated wt\% moisture identified earlier in this chapter.

\subsection{EVALUATION AND RESULTS}

The uncorrelated ( 1 iquid density and water fraction properties are correlated, so they are combined into a single term) uncertainty equation can be stated mathematically as:

$$
\Delta M C=\sqrt{\left(\frac{\partial M C}{\partial \theta} \delta \theta\right)^{2}+\left(\frac{\partial M C}{\partial \sigma_{N}} \delta \sigma_{N}\right)^{2}+\left(\frac{\partial M C}{\partial \rho_{S}} \delta \rho_{S}\right)^{2}+\left(\frac{\partial M C}{\partial \rho_{L}} \delta \rho_{L}+\frac{\partial M C}{\partial\left(\rho_{H_{2} O} / \rho_{L}\right)} \delta\left(\frac{\rho_{H_{2} O}}{\rho_{L}}\right)\right)^{2}}
$$

The uncertainty in the moisture content will be calculated for each of the measured conductivity ranges, $80,60,40,20,10$, and $5 \mathrm{mS} / \mathrm{cm}$. The analytic derivatives are not taken since numerical values were calculated previously. The final results are shown in Table 11. 
Table 11. EMI Inferred Moisture Content with Uncertainties.

\begin{tabular}{|c|c|c|}
\hline $\begin{array}{c}\text { Matrix conductivity } \\
\mathrm{mS} / \mathrm{cm}\end{array}$ & $\begin{array}{c}\text { Moisture content } \\
\text { wt\% } \mathrm{H}_{2} \mathrm{O}\end{array}$ & $\begin{array}{c}\text { Uncertainty } \\
\text { wt\% } \mathrm{H}_{2} \mathrm{O}\end{array}$ \\
\hline 80 & 26.8 & \pm 5.8 \\
\hline 60 & 24.3 & \pm 5.3 \\
\hline 40 & $2 \mathrm{~J} .0$ & \pm 4.6 \\
\hline 20 & 16.1 & \pm 3.6 \\
\hline 10 & 12.1 & \pm 2.8 \\
\hline 5 & 9.0 & \pm 2.1 \\
\hline
\end{tabular}

$\Delta M C\left(80 \frac{m S}{c m}\right)=\sqrt{2.45^{2}+2.06^{2}+1.61^{2}+4.57^{2}} \approx \pm 5.8 w t \% H_{2} O$ $\Delta M C\left(60 \frac{m S}{c m}\right)=\sqrt{2.34^{2}+2.12^{2}+1.53^{2}+4.02^{2}} \approx \pm 5.3 w t \% H_{2} O$ $\Delta M C\left(40 \frac{\mathrm{mS}}{\mathrm{cm}}\right)=\sqrt{2.15^{2}+1.94^{2}+1.40^{2}+3.34^{2}} \approx \pm 4.6 \mathrm{wt \%} \mathrm{H}_{2} \mathrm{O}$

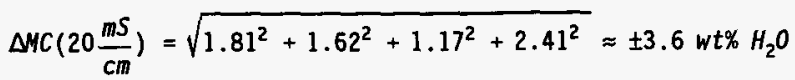
$\Delta M C\left(10 \frac{\mathrm{mS}}{\mathrm{cm}}\right)=\sqrt{1.45^{2}+1.30^{2}+0.93^{2}+1.71^{2}} \approx \pm 2.8 w t \% \mathrm{H}_{2} \mathrm{O}$ $\Delta M C\left(5 \frac{m S}{c m}\right)=\sqrt{1.13^{2}+1.00^{2}+0.72^{2}+1.21^{2}} \approx \pm 2.1 w t \% H_{2} \mathrm{O}$ 


\subsection{CONCLUSIONS}

The measurement of electrical conductivity by the EMI technique is an established method used for well-logging by Geophysicists since the 1940's. There are standard relationships used, such as Archie's Law which relate moist solid electrical conductivity to conductivity of the interstitial liquids, ard other medium properties.

The electrical conductivity of typical Hanford HLW tank interstitial liquids was defined in experiments with different mixtures of chemicals to determine the electrical conductivity contribution from $\mathrm{NaNO}_{3}, \mathrm{NaNO}_{2}, \mathrm{NaOH}$, and $\mathrm{NaAlO}_{2}$.

EMI hardware has been acquired. Laboratory tests demonstrate the increase in EMI response with electrical conductivity in the test stand medium. The EMI technique has been used in the tank farms to scan $10 \mathrm{HLW}$ tanks, and results were compared to the neutron probe, gamma probe, and other EMI scans performed at different frequencies or different coil spacings.

This technology has been transferred from Pacific Northwest Laboratory to WHC and is available to measure moisture content or interstitial liquid level.

The advantages of the EMI probe are as follows:

- Very sensitive to loss of hydraulic conductivity

- Infers free-water content, since electrical conductivity is not affected by bound water

- High vertical spatial resolution dependent on EMI coil spacing

- High radial spatial resolution dependent on EMI coil spacing with multiple depth interrogations possible in a single scan

- Ability to look through adjacent regions to deeper regions

- Sensitive to small changes in material properties

- Light in weight and has low power requirements.

\subsection{REFERENCES}

Archie, G. E., 1942, The Electrical Resistivity Log as an Aid in Determining Source Reservoirs Characteristics, Transactions of the American Institute of Mining Engineering, 146, 54. 
Crowe, R. D. and W. D. Wittekind, 1995, Ferrocyanide Safety Program: In-Tank Application of Electromagnetic Induction (EMI) Moisture Measurements FY 1995 Report, WHC-SD-WM-ER-520, Rev. 0, Westinghouse Hanford Company, Richland, Washington.

Dewan, J. T., 1963, Essentials of Modern Open-Hole Log Interpretation, PennWell Books, PennWell Publishing Company, Tulsa, Oklahoma.

DeWeese, G. C., 1988, Observed Porosities of Single-Shell Tank Waste Salt Cakes and sludges, WHC-SD-WM-TI-328, Rev. 0, Westinghouse Hanford Company, Richland, Washington.

de Witte, Leendert, 1950, Relations Between Resistivities and Fluid Contents of Porous Rocks, "The 011 and Gas Journal", p. 120-132, August 24, 1953.

Harned, H. S. And B. B. Owen, 1950, The Physical Chemistry of Electrolytic Solutions, American Chemical Society Monograph Series, Reihold Publishing Corporation, New York, New York.

Hearst, J. R., and P. H. Nelson, 1985, Well Logging for Physical Properties, McGraw-Hi11 Book Company, New York, New York.

Patwardhan, V. S., and A. Kumar, 1986a, A Unified Approach for Prediction of Properties of Aqueous Mixed-Electrolyte Solutions Part I: Vapor Pressure and Heat of Vaporization, AIChE Journal, 32:1419,1428,

Patwardhan, V. S., and A. Kumar, 1986b, A Unified Approach for Prediction of Properties of Aqueous Mixed-Electrolyte Solutions Part II: Volume, Thermal and Other Properties, AIChE Journal, 32:1429,1438,

Patwardhan, V. S., and A. Kumar, 1993, Thermodynamic Properties of Aqueous Solutions of Mixed Electrolytes: A New Mixing Rule, AIChE Journal, $39: 711,714$,

Reynolds, D. A., and D. L. Herting, 1984, Solubilities of Sodium Nitrate, Sodium Nitrite, and Sodium Aluminate in Simulated Nuclear Waste, Rockwell Hanford Operations (RHO-RE-ST-14 P), Richland, Washington.

Söhnel, 0. and P. Novotnỳ, 1985, Densities of Aqueous Solutions of Inorganic Substances, Elsevier, New York, New York.

Serra, 0., 1984, Fundamentals of Well-Log Interpretation, Elsevier Publishing Company,

Shabtaie, S. and C.R. Bentley, 1995, Electrical resistivity sounding of the East Antarctic ice Sheet, Journal of Geophysical Research, 100 (B2) : 1933-1954

Simmons, C. S., 1995, A Simplified Model of Saltcake Moisture Distribution, Pacific Northwest Laboratory (PNL-10803), Richland, Washington.

Tromp, T.K., P. VanCappellen; , and R.M. Key, 1995, A global model of the early digenesis of organic carbon and organic phosphorus in marine sediments, Geochimica et Cosmochimica Acta, 59(7):1259,1284. 
Van Vleet, R. J., 1993a, Radionuclide and Chemical Inventories for the DoubleShell Tanks, WHC-SD-WM-TI-543, Rev. 1, Westinghouse Hanford Company, Richland, Washington.

Van Vleet, R. J., 1993b, Radionuclide and Chemical Inventories for the Single-Shell Tanks, WHC-SD-WM-TI-565, Rev. 1, Westinghouse Hanford Company, Richland, Washington.

Wait, J. R., 1971, Electromagnetic Probing in Geophysics, The Golem Press, Boulder, Colorado.

Weast, Robert C., 1976, CRC Handbook of Chemistry and Physics, CRC Press, Cleveland ohio.

Wong Po-Zen, J. Koplik and J.P. Tomanic, 1984, Conductivity and Permeability of Rocks, Physical Review B Vol. 30, No. 11, p. 6606-6614,

Wyllie, M.R.J. and A.R. Gregory, 1953, Formation Factors of Unconsolidated Porous Media: Influence of Particle Shape and Effect of Cementation, Petroleum Transactions, AIME, 198:103,110,

Yadav, G.S., 1995, Relating hydraulic and geoelectric parameters of the Jayant aquifer, India, Journal of Hydrology, 167:23-38,

\subsection{ACKNOWLEDGEMENTS}

Several individuals other than authors, made contributions that enhance this document.

D. L. Lessor and D. R. Rector, the independent reviewers from Pacific Northwest National Laboratory, are responsible for contributing the mixing rule calculation for solution density and water fraction documented in Appendix C. Also, D. L. Lessor also contributed discussions on EMI technology, Archie's Law, sampling, and modeling.

K. D. Lambert worked to constructed the spreadsheet files to propagate individual parameter uncertainties into the calculated moisture content. 
WHC-SD-WM-ER-531 REV 0

This page intentionally left blank. 
WHC-SD-WM-ER-531 REV 0

APPENDIX A

TEMPERATURE DISTRIBUTION CALCULATION FOR

A LIQUID OBSERVATION WELL

A-1 
WHC-SD-WM-ER-531 REV 0

This page intentionally left blank. 
The problem is to estimate the steady state temperature distribution in a waste tank with uniform thermal properties and uniform heat generation. The problem is to find the solution for the steady-sate temperature distribution $T(r, z)$ in a solid cylinder where $a, 0 \leq r \leq b, 0 \leq z \leq a$, with heat generation at a constant rate of $g_{0}$ per unit volume and constant thermal conductivity $k_{u}$, while all boundaries are subject to convective heat transfer boundary conditions.

The mathematical formulation of the problem is as follows:

$$
\begin{aligned}
\frac{\partial^{2} T}{\partial r^{2}}+\frac{1}{I} \frac{\partial T}{\partial r}+\frac{\partial^{2} T}{\partial z^{2}}=-\frac{g_{0}}{k_{w}} & \text { in } 0 \leq r \leq b, 0 \leq z \leq a \\
\left.k_{w} \frac{\partial T}{\partial r}\right|_{r=b}+h_{0} T(r=b)=0 & \text { at } r=b \\
-\left.k_{w} \frac{\partial T}{\partial z}\right|_{z=0}+h_{1} T(z=0)=0 & \text { at } z=0 \\
\left.k_{w} \frac{\partial T}{\partial z}\right|_{z=a}+h_{2} T(z=a)=0 & \text { at } z=a
\end{aligned}
$$

A new variable $\theta(r, z)$ is defined to remove the inhomogeneous term in Equation (1).

$$
\begin{aligned}
T(I, z) & =\theta(r, z)+\frac{g_{0}}{k_{w}}\left(-\frac{z^{2}}{2}+c_{1} z+c_{2}\right) \\
& =\theta(r, z)+f(z)
\end{aligned}
$$

The function $f(z)$ is comparable to a temperature profile in a one dimensional slab and must satisfy the following boundary conditions.

$$
\begin{array}{rlr}
-\left.k_{w} \frac{\partial f}{\partial z}\right|_{z=0}+h_{1} f(z=0) & =0 & \text { at } z=0 \\
\left.k_{w} \frac{\partial f}{\partial z}\right|_{z=a}+h_{2} f(z=a) & =0 & \text { at } z=a
\end{array}
$$


As long as there is heat generation (e.g. $g_{0}>0, f(z)$ there will be a maximum value within the allowable range of $z$. The temperature profile in the waste tanks typically exhibit a maximum value near the bottom of the tank. It can be shown by setting the derivative of $f(z)$ equal to zero, the constant: $c_{1}$ is the axial location of the maximum temperature, $z_{m}$.

$$
\begin{gathered}
\frac{d f}{d z}=\frac{g_{0}}{k_{w}}\left(-z_{\mathrm{m}}+c_{1}\right)=0 \\
\Rightarrow c_{1}=z_{\mathrm{m}}
\end{gathered}
$$

The constant $c_{2}$ is found from the boundary condition for $f(z)$ at $z=0$.

$$
\begin{aligned}
-\left.k_{w} \frac{d f}{d z}\right|_{z=0}+h_{0} f(z=0) & =-k_{w} \frac{g_{0}}{k_{w}}\left(z_{m}\right)+h_{1} \frac{g_{0}}{k_{w}}\left(c_{2}\right)=0 \\
& \Rightarrow c_{2}=\frac{k_{w} z_{m}}{h_{1}}
\end{aligned}
$$

Using the boundary condition for $f(z)$ at $z=a, h$, can be expressed in terms of $c_{1}$ and $c_{2}$.

$$
\begin{gathered}
\left.\mathrm{k}_{\mathrm{w}} \frac{\mathrm{df}}{\mathrm{dz}}\right|_{\mathrm{z}=\mathrm{a}}+h_{2} f(a)=k_{w} \frac{g_{0}}{k_{w}}\left(-a+z_{m}\right)+h_{2} \frac{g_{0}}{k_{w}}\left(-\frac{a^{2}}{2}+z_{m} a+\frac{k_{w}}{h_{1}} z_{m}\right)=0 \\
\quad h_{2}=\frac{k_{w}\left(a-z_{m}\right)}{-\frac{a^{2}}{2}+z_{m}\left(a+\frac{k_{w}}{h_{1}}\right)}
\end{gathered}
$$

The arbitrary constants $c_{1}$ and $c_{2}$, are chosen in this way to simplify the probiem to Equation (7) as follows. 


$$
\begin{aligned}
& \frac{\partial^{2} \theta}{\partial r^{2}}+\frac{1}{r} \frac{\partial \theta}{\partial r}+\frac{\partial^{2} \theta}{\partial z^{2}}=0 \quad \text { in } 0 \leq r \leq b, 0 \leq z \leq a \\
&\left.k_{w} \frac{\partial \theta}{\partial r}\right|_{r=b}+h_{0} \theta(r=b)=-h_{0} f(z) \quad \text { at } r=b \\
&-\left.k_{w} \frac{\partial \theta}{\partial z}\right|_{z=0}+h_{1} \theta(z=0)=0 \quad \text { at } z=0 \\
&\left.k_{w} \frac{\partial \theta}{\partial z}\right|_{z=a}+h_{2} \theta(z=a)=0 \quad \text { at } z=a
\end{aligned}
$$

The solution to Equation (7) can be written as a product of two functions, $\theta=\Sigma_{m} \theta_{m}$, and $\theta_{m}(r, z)=R_{m}(r) Z_{m}(z)$.

$$
\begin{aligned}
& R_{m}(r)=I_{0}\left(\eta_{m} r\right) \\
& Z_{m}(z)=\eta_{m} \cos \left(\eta_{m} z\right)+\frac{h_{1}}{k_{w}} \sin \left(\eta_{m} z\right)
\end{aligned}
$$

and

$$
\begin{aligned}
\eta_{m} & =m^{\text {th }} \text { root of } g(\eta) \\
g(\eta) & =\eta\left(\frac{h_{1}}{k_{w}}+\frac{h_{2}}{k_{w}}\right) \cos (\eta a)+\left(\eta^{2}+\frac{h_{1}}{k_{w}} \frac{h_{2}}{k_{w}}\right) \sin (\eta a)
\end{aligned}
$$

A solution for $\theta(r, z)$ can be written and is constructed using these functions.

$$
\theta(r, z)=\sum_{m=1}^{\infty} \frac{-h_{0} I_{0}\left(\eta_{m} r\right)}{h_{0} I_{0}\left(\eta_{m} b\right)+k_{w} \eta_{m} I_{1}\left(\eta_{m} b\right)} A_{m .} Z\left(\eta_{m}, z\right)
$$

The application of the boundary condition at $r=b$ is used to determine the coefficients $A_{m}$. 


$$
A_{m}=\frac{\int_{0}^{a} f\left(z^{\prime}\right) z\left(\eta_{m}, z^{\prime}\right) d z^{\prime}}{\int_{0}^{a} z\left(\eta_{m}, z^{\prime}\right)^{2} d z^{\prime}}
$$

Equations (8), (9), (10), and (11) form a complete solution for describing problems in terms of an infinite series. Table A-1 gives some representative values for the $A_{m}$ coefficients for conditions characteristic of waste Tank 241-BY-104.

Table A-1. Typical Values for Expansion Coefficients and Eigenvalues.

\begin{tabular}{|c|c|c|}
\hline$m$ & $n_{m}\left(\mathrm{ft}^{-1}\right)$ & $A_{m}(\mathrm{ft} \mathrm{F})$ \\
\hline 1 & 0.136 & 20.1 \\
\hline 2 & 0.361 & 0.85 \\
\hline 3 & 0.594 & 0.22 \\
\hline 4 & 0.829 & 0.07 \\
\hline 5 & 1.065 & 0.03 \\
\hline
\end{tabular}

Since the first expansion coefficient $A_{1}$ is much 1 arger than the rest of the coefficients, $f(z)$ can be approximated with a single term.

$$
f(z) \approx A_{1} Z\left(\eta_{1}, z\right)
$$

This allows the spatial temperature in the waste tank to be expressed in the following simplified form.

$$
\begin{aligned}
\theta(I, z) & =\frac{-h_{0} I_{0}\left(\eta_{1} r\right)}{h_{0} I_{0}\left(\eta_{1} b\right)+k_{w} \eta_{1} I_{1}\left(\eta_{1} b\right)} \quad A_{1} z\left(\eta_{1}, z\right) \\
& =-f(z)\left[\frac{h_{0} I_{0}\left(\eta_{1} r\right)}{h_{0} I_{0}\left(\eta_{1} b\right)+k_{w} \eta_{1} I_{1}\left(\eta_{1} b\right)}\right]
\end{aligned}
$$


Finally, by combining this Equation (13) with Equation (2) and expressing $f(z)$ in terms of the known parameters, the desired result is obtained.

$$
\begin{aligned}
T(r, z) & =f(z)+\theta(r, z) \\
& =T_{v p}+\frac{g_{0}}{k_{w}}\left[\frac{-z^{2}}{2}+z_{m}\left(z+\frac{k_{w}}{h_{1}}\right)\right]\left[1-\frac{h_{0} I_{0}\left(\eta_{1} r_{10 w}\right)}{h_{0} I_{0}\left(\eta_{1} b\right)+k_{w} \eta_{1} I_{1}\left(\eta_{1} b\right)}\right]
\end{aligned}
$$

The following specific information is needed to apply Equation (14) to a specific tank.

- Waste volume or waste height.

- Heat load.

- Radial location of thermocouple tree.

- Radial location of liquid observation well.

- Vapor space temperature.

- Maximum waste temperature.

- Axial location of maximum temperature.

- Heat transfer coefficient at the surface of waste.

The waste volume and heat load are used to determine the average volumetric heat generation rate, $g_{0}$. The measured vapor space and peak temperatures used together with the axial location of the peak temperature, $z_{m}$, determine the average thermal conductivity, $k_{\mathrm{w}}$. The radial position of the liquid observation we $1, r_{\text {low }}$, is used to correct for the radial temperature gradient. 
WHC-SD-WM-ER-531 REV 0

This page intentionally left blank. 
WHC-SD-WM-ER-531 REV 0

APPENDIX B

ARCHIE'S LAN STATUS AND

CHOICE OF CONSTANTS

B-1 
WHC-SD-WM-ER-531 REV 0

This page intentionally left blank. 
Appendix B discusses Archie's law status, applicability, and the logic for choice of constants.

Archie's law was first proposed (Archie 1942) to correlate electrical conductivity of an electrically conductive solution in an electrically conductive porous solid matrix. There has been a great deal of research in correlating resistivity of a rock with the water content (Carmichael 1989). These studies have led to the widespread use of Archie's law, which is an empirical formula relating resistivity and porosity as shown.

$$
\rho_{\mathrm{t}}=\mathrm{a} \rho_{\mathrm{w}} \theta^{-\mathrm{m}} \quad\left(\mathrm{S}_{\mathrm{w}}=1\right)
$$

where

$$
\begin{aligned}
& \rho_{\mathrm{t}}=\text { the bulk resistivity of the rock liquid matrix } \\
& \rho_{\mathrm{w}}=\quad \begin{array}{l}
\text { the resistivity of the electrolytic liquid that is in the porous } \\
\text { volume }
\end{array} \\
& \theta=\begin{array}{l}
\text { the porosity expressed as a fraction per unit volume of the solid } \\
\text { matrix }
\end{array}
\end{aligned}
$$

$a, m=$ parameters whose values are assigned arbitrarily to make the equation fit a particular group of measurements.

Table B-1 shows an example of the a and $m$ values referenced from Carmichael (1989), Table 14, p. 387.

Calculated magnitudes of the formation factor $\left(\rho_{\mathrm{t}} / \rho_{\mathrm{k}}\right)$, using the values of $a$ and $m$ are shown in Table B-2.

The key points to be noted from the data presented in this table is the magnitude of the formation factors in the first two columns. Those formulation factors expected to be most similar to Hanford HLW tank contents are not that much different in magnitude at porosity $\theta=0.35$.

Shown in Figure B-1 is a graph for these different rock types with $1 / \rho_{u}=\sigma_{w}=200 \mathrm{mS} / \mathrm{cm}$. Four types are fairly similar but lava, which was suddenly solidified, is different. Hanford HLW salt cake is expected to follow the crystalline, sedimentary, detrital rock curves. 
Table B-1. Forms of Archie's Law.

\begin{tabular}{|l|l|c|c|}
\hline \multicolumn{1}{|c|}{ FORMS OF ARCHIE'S LAW THAT MAY BE USED WHEN LITHOLOGY OF A ROCK IS KNOWN } \\
\hline 1 & \multicolumn{1}{|c|}{ Description of Rock } & $\mathrm{a}$ & $\mathrm{m}$ \\
\hline 1 & $\begin{array}{l}\text { Weakly-cemented detrital rocks, such as sand, sandstone } \\
\text { and some 1 imestones, with a poros ity range from 0.25 to } \\
0.45, \text { usually Tertiary in age. }\end{array}$ & 0.88 & 1.37 \\
\hline 2 & $\begin{array}{l}\text { Moderately-cemented sedimentary rocks, including } \\
\text { sandstones and 1 imestones, with a porosity range from } \\
0.18 \text { to 0.35, usually Mesozoic in age. }\end{array}$ & 0.62 & 1.72 \\
\hline 3 & $\begin{array}{l}\text { Firmly-cemented sedimentary rocks with a porosity range } \\
\text { from 0.05 to 0.25, usually Paleozoic in age. }\end{array}$ & 0.62 & 1.95 \\
\hline 4 & $\begin{array}{l}\text { Highly porous volcanic rocks, such as tuff, aa and } \\
\text { pahoehoe, with porosity in the range 0.20 to 0.80. }\end{array}$ & 3.5 & 1.44 \\
\hline 5 & $\begin{array}{l}\text { Rocks with less than 0.04 porosity, including dense } \\
\text { igneous rocks and metamorphosed sedimentary rocks. }\end{array}$ & 1.4 & 1.58 \\
\hline
\end{tabular}

$a=$ Archie's Law constant of proportionality

$\mathrm{m}=$ Archie's Law constant porosity exponent in $\rho_{\mathrm{t}}=\mathrm{a} \rho_{\mathrm{w}} \theta^{-\mathrm{m}}$.

Table B-2. Formation Factor Calculation.

\begin{tabular}{|c|c|c|c|c|c|}
\hline Porosity & $0.88 \theta^{-1.37}$ & $0.62 \theta^{-1.72}$ & $0.62 \theta^{-1.95}$ & $3.50 \theta^{-1.44}$ & $1.40 \theta^{-1.58}$ \\
\hline 0.60 & & & & 7.30 & \\
\hline 0.55 & & & & 8.28 & \\
\hline 0.50 & & & & 9.50 & \\
\hline 0.45 & 2.63 & & & 11.05 & \\
\hline 0.40 & 3.09 & & & 13.09 & \\
\hline 0.35 & 3.71 & 3.77 & & 15.87 & \\
\hline 0.30 & 4.58 & 4.92 & & 19.82 & \\
\hline 0.25 & 5.88 & 6.73 & 9.26 & 25.77 & \\
\hline 0.20 & & 9.88 & 14.30 & 35.53 & \\
\hline 0.15 & & & 25.06 & & \\
\hline 0.10 & & & 55.26 & & \\
\hline 0.05 & & & 213.50 & & 159.13 \\
\hline 0 & & & & & \\
\hline
\end{tabular}




\section{Archie's Law Comparison}

\section{Sedimentary - 3, Volcanic \& Crystalline}

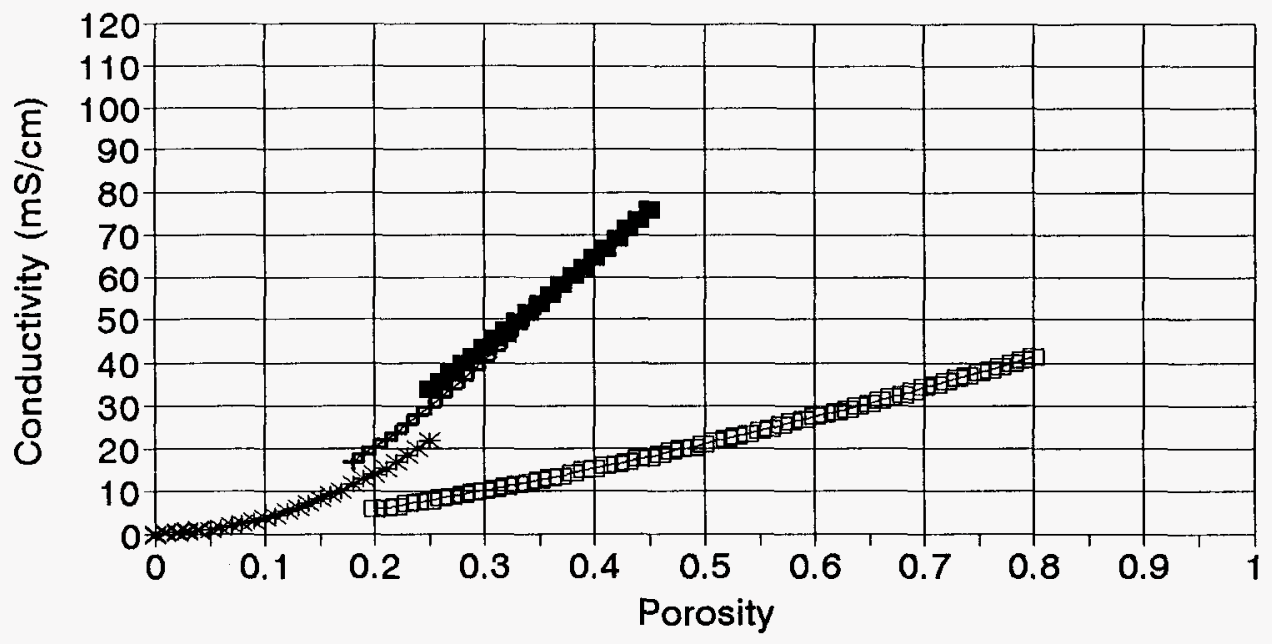

$\begin{array}{ll}\rightarrow-\text { Sediment.-Young } & + \text { Sediment.-Older } * \text { Sediment.-Ancient } \\ -\square \text { Volcanic } & * \text { Crystalline }\end{array}$




\section{WHC-SD-WM-ER-531 REV 0}

\section{REFERENCES}

Archie, G. E., 1942, The Electrical Resistivity Log as an Aid in Determining Some Reservoirs Characteristics, Transactions of the American Institute of Mining Engineering, 146, 54, 1942.

Carmichael, R. S., 1989, CRC Practical Handbook of Physical Properties of Rock and Minerals, "Electrical Properties" by George V. Keller, p. 359, 1989. 
WHC-SD-WM-ER-53I REV 0

APPENDIX C

LIQUID DENSITY AND WATER

FRACTION CALCULATION

C-1 
WHC-SD-WM-ER-531 REV 0

This page intentionally left blank.

C-2 
Introduction for Laboratory Solution Data

This is the mathematical calculation of HLW tank liquid density and water fraction. The liquid density and water fraction are used to convert from liquid volume to weight percent water. The liquid density is calculated by two different methods and compared to laboratory measured densities of a $\mathrm{H}_{2} \mathrm{O}$, $\mathrm{NaNO}_{3}, \mathrm{NaNO}_{2}, \mathrm{NaOH}$, and $\mathrm{NaAlO}_{2}$ mixed solution. The first density calculation method is by a least squares fit to specific gravity data. The second density calculation method is by a mixing rule.

Assumptions

The HLW tank liquid is predominantly a mixture of $\mathrm{H}_{2} \mathrm{O}, \mathrm{NaNO}_{3}, \mathrm{NaNO}_{2}$, $\mathrm{NaOH}$, and $\mathrm{NaAlO}_{2}$, with other, minor, constituents.

Discussion - Least Squares Fit to Specific Gravity Data

253 specific gravities were measured (Reynolds and Herting 1984) and a least squares fit was accomplished to this data. A correlation for density was calculated in terms of temperature and either molality or molarity for the $\mathrm{NaNO}_{3}, \mathrm{NaNO}_{2}, \mathrm{NaOH}$, and $\mathrm{NaAlO}_{2}$ in solution.

The correlation was compared to 45 densities measured as part of the electrical conductivity as a function of composition and temperature measurements. The Reynolds and Herting correlation compared reasonably with the experimental measurements:

$$
\text { Density }_{\text {R\&H }} \text { - Density } \text { Expt. }=+0.018651 \pm 0.034428 \mathrm{~g} / \mathrm{cm}^{3}
$$

This is considered to be acceptable agreement with the Density Expt. for laboratory solution data.

Discussion - Mixing Rule Calculation for Specific Gravity

This specific gravity averaging theory (Patwardhan and Kumar, 1993) was applied to a mixture of $\mathrm{NaNO}_{3}, \mathrm{NaNO}_{2}, \mathrm{NaOH}$ and $\mathrm{NaAlO}_{2}$. A numerical relationship for $\mathrm{NaNO}_{3}, \mathrm{NaNO}_{2}$, and $\mathrm{NaOH}$ densities (Sôhnel and Novotnỳ, 1985) was calculated in terms of temperature and molarity. The $\mathrm{NaAlO}_{2}$ density was approximated by assuming the same density relationship as $\mathrm{NaNO}_{3}$ in aqueous solution.

The theoretical mixing rule calculation was compared to 45 densities measured as part of the electrical conductivity as a function of composition and temperature measurements. The theoretical relation compared excellently with the experimental measurements:

$$
\text { Density }_{\mathrm{mr}} \text { - Density } \text { Expt. }=+0.001776 \pm 0.010857 \mathrm{~g} / \mathrm{cm}^{3}
$$

This is considered to be excellent agreement with the Density Expt. for laboratory solution data. 
Introduction for 35 Analyzed HLW Tank Liquid Samples

A number of HLW tank liquids have been analyzed. Some did not have a sufficient proportion of the salts in solution measured in order to predict the liquid density, but 35 analyzed HLW tank solutions did have the molarity for $\mathrm{NaNO}_{3}, \mathrm{NaNO}_{2}, \mathrm{NaOH}$, and $\mathrm{NaAlO}_{2}$ in solution. These solutions were not saturated solutions, and there was a wide range of densities and water fractions.

These HLW tank solution densities were calculated by the least squares method and by the mixing rule method. The water proportion of the tank solution was calculated for these analyzed tank solutions.

\section{Discussion - Least Squares Fit for Water Fraction}

These solution densities were calculated by the least squares method. The analyzed HLW tank solution density was subtracted from the least squares fit to these analyzed liquids.

$$
\text { Density }_{\text {R\&H }}-\text { Density }_{\text {Expt. }}=-0.102211 \pm 0.196342 \mathrm{~g} / \mathrm{cm}^{3}
$$

These results indicate that some solid particles drained into the liquid, raising the liquid density above the calculated aqueous solution density.

Discussion - Mixing Rule Calculation for Water Fraction

These solution densities were calculated by the mixing rule method. The analyzed HLW tank solution density was subtracted from the mixing rule calculation for these analyzed liquids.

$$
\text { Density }_{\mathrm{mr}} \text { - Density } \text { Expt. }=-0.129426 \pm 0.185865 \mathrm{~g} / \mathrm{cm}^{3}
$$

These results indicate that some solid particles drained into the liquid, raising the liquid density above the calculated aqueous solution density.

Calculations continue considering the calculated solution density and water fraction by the mixing rule method only.

$$
\begin{aligned}
& \text { Density } y_{\text {Analyzed Solutions }}\left(\rho_{\mathrm{L}}\right)=1.177432 \pm 0.094255 \mathrm{~g} / \mathrm{cm}^{3} \\
& \mathrm{H}_{2} \mathrm{O} \text { Fraction }\left(\rho_{\mathrm{HzO}} / \rho_{\mathrm{L}}\right)=0.792408 \pm 0.109754
\end{aligned}
$$

The solution density and the water fraction of the solution are correlated, the higher the solution density, the lower the $\mathrm{H}_{2} \mathrm{O}$ fraction. The uncertainty in EMI moisture content calculation takes into account that these uncertainties are correlated.

Figure $C-1$ shows the mixing rule calculation for density of the analyzed waste tank solutions versus water fraction. 


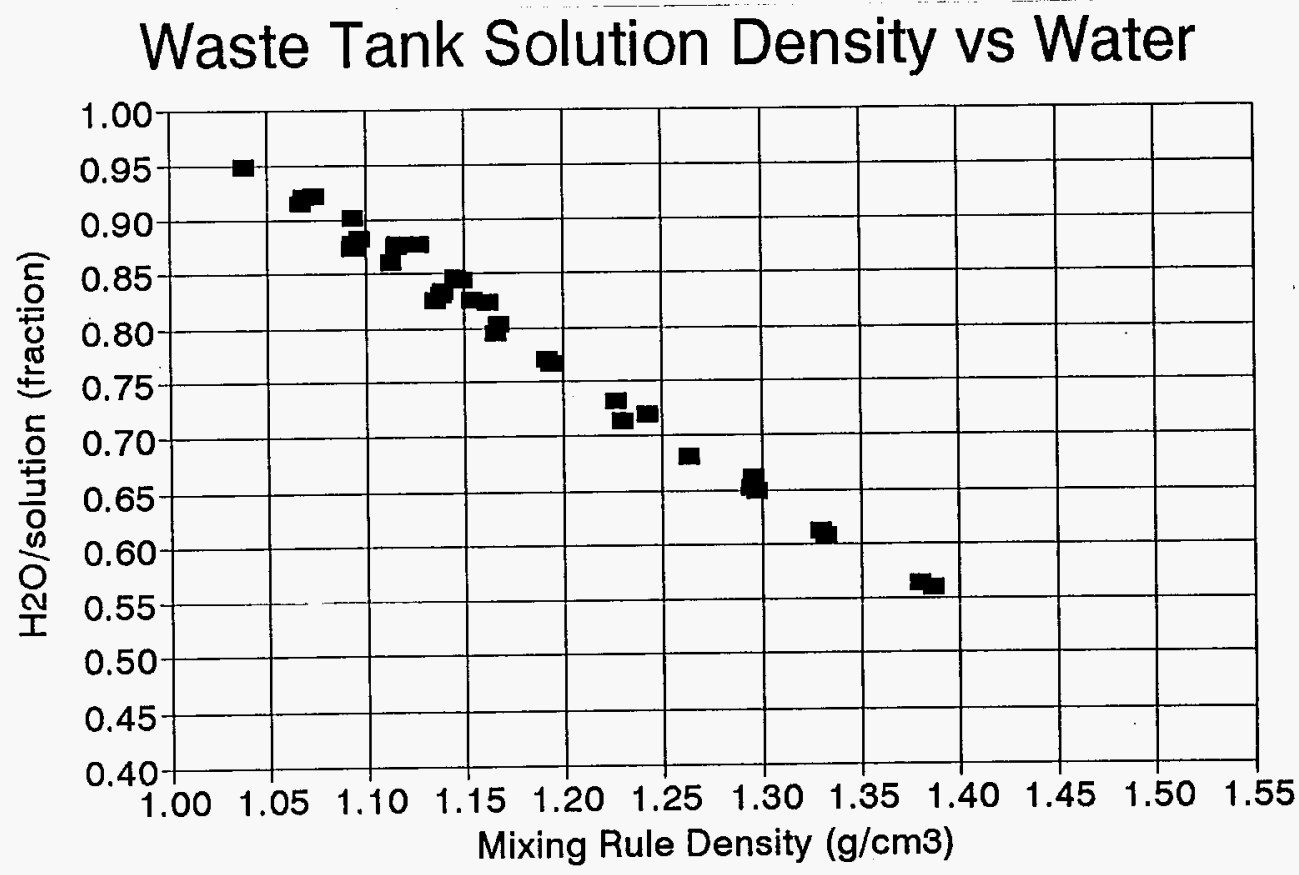

a $\mathrm{H}_{2} \mathrm{O}$ fraction $\mathrm{mr}$ 
FORTRAN Computer Coding for Comparison to 45 Test Mixture Densities

C FORTRAN COMPUTER PROGRAM TO CALCULATE HLW TANK

C INTERSTITIAL LIQUID DENSITY AND WATER FRACTION.

C A FOUR COMPONENT SYSTEM IS CONSIDERED: SODIUM HYDROXIDE,

c SODIUM NITRATE, SODIUM NITRITE, AND SODIUM ALUMINATE.

REF: THERMODYNAMIC PROPERTIES OF AQUEOUS SOLUTIONS OF MIXED ELECTROLYTES: A NEW MIXING RULE, PATWARDHAN \& KUMAR IN AICHE JOURNAL, APRIL 1993, VOL. 39, N0.4, P.711-714.

REF: DENSITIES OF AQUEOUS SOLUTIONS OF INORGANIC SUBSTANCES BY OTAKAR SOHNEL AND PETR NOVOTNY, 1985.

C TEST MATRIX PROGRAM

1 READ (5, 100, END=2) ICASE, TMOH(K), TMALO2(K),

\& TMNO3(K), TMNO2(K), DENFIT(K), DENEXP(K)

100 FORMAT (I12, 4F9.0, 8X, 2F10.0)

WRITE $(6,99)$ ICASE, TMNO3(K), TMNO2(K), TMOH(K),

\& TMALO2(K), DENFIT $(K)$, DENEXP(K)

99 FORMAT (I4, 4F9.3,8X, 2F10.3,3X, 'ECHO INPUT')

$\mathrm{K}=\mathrm{K}+1$

C

GOTO 1

$2 \mathrm{KK}=\mathrm{K}-1$

$\mathrm{K}=1$

$T=25.0$

C CALCULATED WATER DENSITY AT TEMPERATURE $=25 \mathrm{C}$

C USING QUADRATIC LAGRANGIAN INTERPOLATING POLYNOMIAL. RHOWAT $=(T-25) *.(T-60) * .1 . /((3.98-25) *.(3.98-60))+$.

\& $(T-3.98) *(T-60) * 0.99707 /.((25 .-3.98) *(25 .-60))+$.

\& $(T-3.98) *(T-25) * 0.98324 /.((60 .-3.98) *(60 .-25)$.

$T 2=T * * 2$

SUM1A $=0.0$

SUM1B $=0.0$

SUM $2 A=0.0$

SUM $2 B=0.0$

C

THESE CORRELATIONS ARE FROM SOHNEL AND NOVOTNY REFERENCE

$3 \mathrm{C}=$ TMNO3 (K) + TMNO2 (K) + TMOH (K) +TMALO2 (K)

C NaOH DENSITY AT SAME STRENGTH AS MIXED SOLUTION

RHONOH $=(4.916 E 1-9.064 E-2 * T+6.308 E-4 * T 2) * C$ 
$+(-4.907+1.633 \mathrm{E}-2 * \mathrm{~T}-1.041 \mathrm{E}-4 * \mathrm{~T} 2) *(\mathrm{C} * 1.5)$

RHONOH=RHOWAT+RHONOH* $1 . E-3$

C NaNO3 DENSITY AT SAME STRENGTH AS MIXED SOLUTION

RHONO3 $=(6.298 \mathrm{E} 1-2.382 \mathrm{E}-1 * \mathrm{~T}+1.520 \mathrm{E}-3 * \mathrm{~T} 2) * \mathrm{C}$

$\&+(-4.138+6.626 \mathrm{E}-2 * \mathrm{~T}-4.208 \mathrm{E}-4 * \mathrm{~T} 2) *(C * \star 1.5)$

RHONO3=RHOWAT+RHONO3* $1 . E-3$

C NaNO2 DENSITY AT SAME STRENGTH AS MIXED SOLUTION

RHONO2 $=(5.142 E 1-3.362 E-1 * T+4.079 E-3 * T 2) * C$

$\&+(-3.242+7.155 \mathrm{E}-2 * \mathrm{~T}-9.671 \mathrm{E}-4 * \mathrm{~T} 2) *(\mathrm{C} * \star 1.5)$

RHONO2 $=$ RHOWAT+RHONO2* $1 . E-3$

C

$\mathrm{I}=1$

RHO(I) $=1.450$

SALTWT $=$ TMOH $(K)$ *TMOLWT (1)+TMNO3 $(K)$ *TMOLWT (2)+TMNO2 $(K)$

\& *TMOLWT(3)+TMALO2(K)*TMOLWT (4)

C

C CALCULATE MOLALITY FROM MOLARITY USING ASSUMED, ITERATED DENSITY

4 TMOLAL $(1)=$ TMOH $(K) /(R H O(I) * 1 . E 3-S A L T W T) * 1 . E 3$

TMOLAL (2) $=$ TMNO3 $(K) /($ RHO $(\mathrm{I}) * 1$. E3-SALTWT $) * 1 . E 3$

TMOLAL $(3)=\operatorname{TMNO} 2(\mathrm{~K}) /(\mathrm{RHO}(\mathrm{I}) * 1 . \mathrm{E3}-\mathrm{SALTWT}) * 1 . \mathrm{E} 3$

TMOLAL $(4)=\operatorname{TMALO2}(K) /($ RHO $(I) * 1 . E 3-S A L T W T) * 1 . E 3$

TMOLSM=TMOLAL (1)+TMOLAL (2)+TMOLAL (3)+TMOLAL (4)

IF $\left(K-10^{*}(K / 10)\right.$. EQ.1) WRITE $(6,98) \mathrm{K}$, I, RHOWAT,

\& RHO(I), SALTWT, (TMOLAL $(J), J=1,4$ ), TMOLSM

C

98 FORMAT $(2 \mathrm{I} 6,3 \mathrm{Fg} .3,3 \mathrm{X}, 5 \mathrm{F9} .3,3 \mathrm{X}$, ' TMOLAL S')

C

THE PSISUM/PSIRHO IS THE MIXING RULE FROM PATWARDIAN AND KUMAR

$\operatorname{PSI}(1)=1 . E 3 *$ TMOLAL $(1) /$ TMOLSM + TMOLAL $(1) *$ TMOLWT $(1)$

$\operatorname{PSI}(2)=1$. E $^{*} *$ TMOLAL (2) $/$ TMOLSM + TMOLAL (2)*TMOLWT (2)

PSI $(3)=1$. E3*TMOLAL (3) $/$ TMOLSM + TMOLAL (3)*TMOLWT (3)

PSI (4) $=1$. E3*TMOLAL (4)/TMOLSM + TMOLAL (4)*TMOLWT (4)

PSISUM $=$ PSI (1)+PSI (2) +PSI (3) +PSI (4)

C APPROXIMATION: NaA102 DENSITY ASSUMED TO BE NaN03 DENSITY

PSIRHO=PSI (1)/RHONOH+PSI (2)/RHONO3+

\& PSI (3)/RHONO2+PSI (4)/RHONO3

$\mathrm{I}=\mathrm{I}+1$

RHO (I) $=$ PSISUM/PSIRHO

IF $(K-10 *(K / 10)$, EQ .1$)$ WRITE $(6,97) K, I, \quad(P S I(J), J=1,4)$,

\& RHONOH, RHONO3, RHONO2, RHO(I-1), RHO(I)

C

97 FORMAT (2I6,4F9.3,3X,5F9.3,3X,'PSI RHOS RHO')

C DENSITY NOT CONVERGED? RECALCULATE MOLALITY FROM ITERATED. DENSITY

IF (ABS(RHO(I)-RHO(I-1)).GT.1.E-4.AND.I.LT.25) GOTO 4

WATPRT $=($ RHO $(\mathrm{I}) * 1000 .-\mathrm{SALTWT}) \star 1 . \mathrm{E}-3$

WTRFRC=WATPRT $/$ RHO (I)

$\mathrm{C}$

DENFIT IS CORRELATION FROM REYNOLDS AND HERTING

$\operatorname{DENFIT}(K)=1.017+5.87 \mathrm{E}-2 \star \mathrm{TMALO}(\mathrm{K})-1.943 \mathrm{E}-2 * \mathrm{TMOH}(\mathrm{K})-5.05 \mathrm{E}-4 *(25.0)$

$\&+4.59 \mathrm{E}-2 *(\mathrm{TMALO} 2(\mathrm{~K})+\mathrm{TMOH}(\mathrm{K})+\mathrm{TMNO3}(\mathrm{K})+\mathrm{TMNO2}(\mathrm{K}))$

\& $-8.83 \mathrm{E}-4^{\star}(\mathrm{TMNO}(\mathrm{K}) *$ TMNO2 $(K))$

IF $(K-10 *(K / 10)$. EQ .1$)$ WRITE $(6,96) K, 1$,

\& PSISUM, PSIRHO, RHO(I), WATPRT, WTRFRC

96 FORMAT (2I6,5F9.3, 3X, 'PSISUM WTRFRC')

H2OPRT $=($ DENF IT (K) * 1. E3 - TMOH $(K) *$ TMOLWT (1) - TMNO3 (K) *TMOLWT (2) 


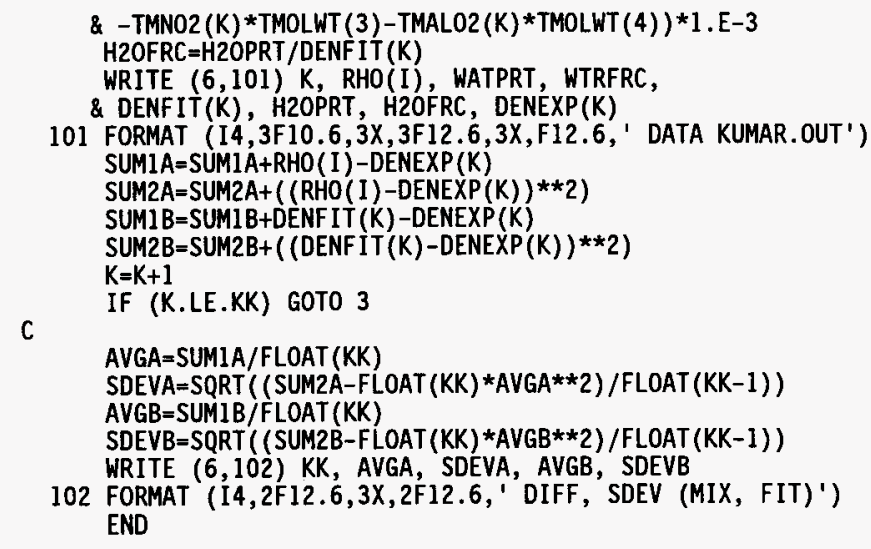


FORTRAN Computer Output for Comparison to 45 Test Mixture Densities

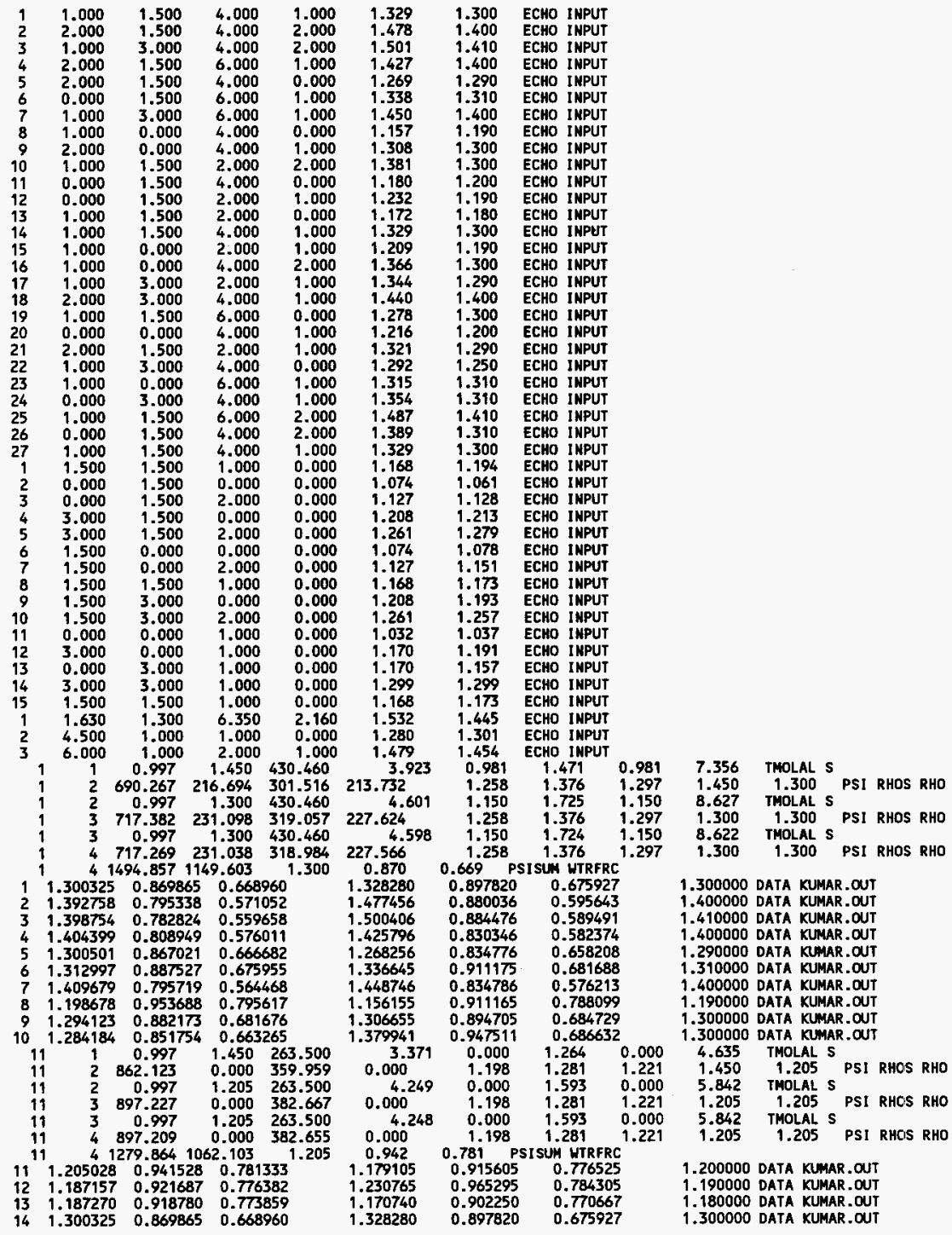




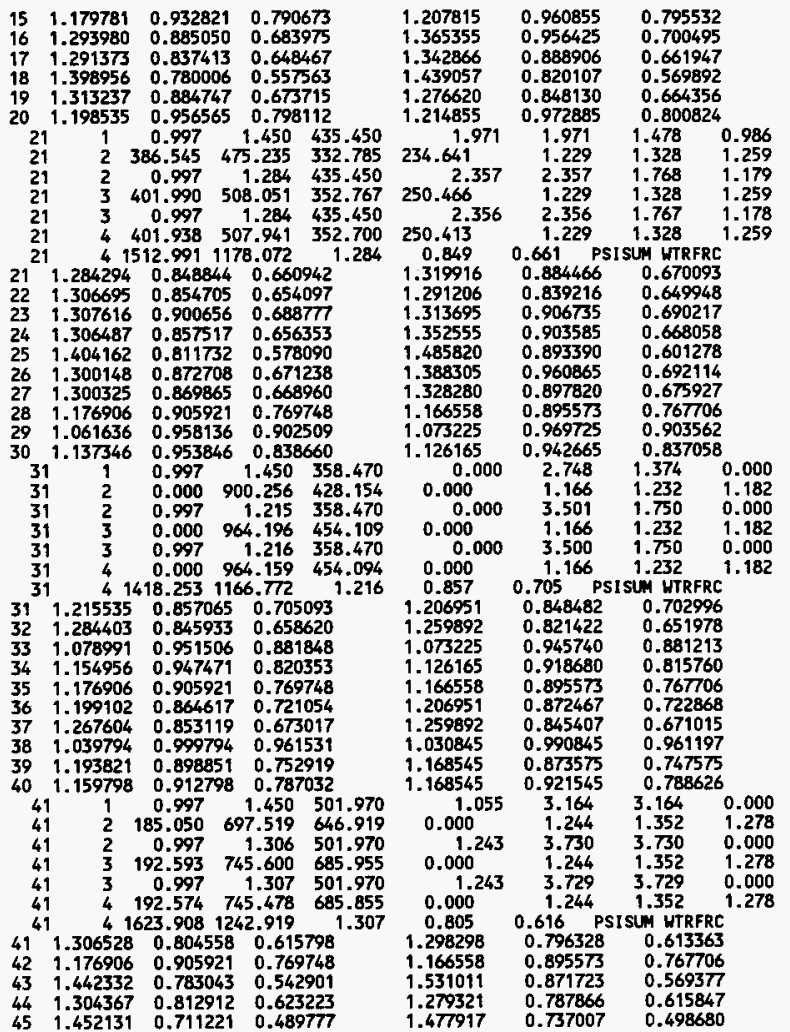

1.190000 DATA KUMAR.OUT

1.300000 DATA KUMAR.OUT

1.290000 DATA KUMAR.OUT

1.400000 DATA KUMAR.OUT

1.300000 DATA KUMAR.OUT

1.200000 DATA KUMAR.OUT

6.407 TMOLAL S

$1.450 \quad 1.284$ PSI RHOS RHO

7.662 TMOLALS

$1.284 \quad 1.284$ PSI RHOS RHO

7.657 TMOLAL S

$1.284 \quad 1.284$ PSI RHOS RHO

1.290000 DATA KUMAR.OUT

1.250000 DATA KUMAR.OUT

1.310000 DATA KLMAR.OUT

1.310000 DATA KUMAR.OUT

1.410000 DATA KUMAR.OUT

1.310000 DATA XUMAR. OUT

1.300000 DATA KUMAR.OUT

1.194100 DATA KUMAR.OUT

1.060800 DATA KUMAR.OUT

1.127500 DATA KUMAR.OUT

4.123 TMOLAL S

$1.450 \quad 1.215$ PSI RHOS RHO

5.251 TMOLAL $\$$

1.2151 .216 PSI RHOS RHO 5.250 TMOLAL S

$1.216 \quad 1.216$ PSI RHOS RHO

1.212800 DATA XUMAR. OUT

1.278900 DATA KUMAR.OUT

1.077600 DATA KUMLR. OUT

1.151000 DATA KUMAR.OUT

1.172700 DATA KLMAR. OUT

1.192700 DATA KLMAR. DUT

1.256500 DATA KUMAR.OUT

1.036800 DATA KUMAR.OUT

1.190700 DATA KUMAR .OUT

1.157300 DATA KUMAR.OUT

7.384 TMOLAL S

$1.450 \quad 1.306$ PSI RHOS RHO

8.704 TMOLAL $\$$

$1.306 \quad 1.307$ PSI RHOS RHO

8.700 TWOLAL S

$1.307 \quad 1.307$ PSI RHOS RHO

1.299100 DATA KUMAR . OUT

1.172600 DATA KUMAR.OUT

1.445400 DATA KUMAR , OUT

1.300800 DATA KUMAR.OUT

1.453600 DATA KUMAR.OUT

$45 \quad 0.001776 \quad 0.010857 \quad 0.0186510 .034628$ DIFF, SDEV (MIX, FIT) 
FORTRAN Computer Coding for Calculating 35 HLW Tank Analyzed Liquids

C FORTRAN COMPUTER PROGRAM TO CALCULATE HLW TANK

C INTERSTITIAL LIQUID DENSITY AND WATER FRACTION.

c

C

C

DATA TMOLWT /40.00, 84.99, 69.00, 81.97/

\section{REF: THERMODYNAMIC PROPERTIES OF AQUEOUS SOLUTIONS OF MIXED}

ELECTROLYTES: A NEW MIXING RULE, PATWARDHAN \& KUMAR IN

AICHE JOURNAL, APRIL 1993, VOL. 39, N0.4, P.711-714.

REF: DENSITIES OF AQUEOUS SOLUTIONS OF INORGANIC SUBSTANCES BY OTAKAR SOHNEL AND PETR NOVOTNY, 1985.

REF: SOLUBILITIES OF SODIUM NITRATE, SODIUM NITRITE, AND SODIUM ALUMINATE IN SIMULATED NUCLEAR WASTE

BY DANIEL A. REYNOLDS AND DANIEL L. HERTING, RHO-RE-ST-14 $P$

DIMENSION TMOH(50), TMNO3(50), TMNO2(50), TMAL02(50)

DIMENSION TMOLAL (4), TMOLWT (4), PSI (4), RHO(25)

DIMENSION DENFIT $(50)$, DENEXP(50); DENMR $(50)$

c MEASURED HLW TANK SAMPLES PROGRAM

1 READ $(5,100$, END $=2)$ ICASE, TMNO3(K), TMNO2 (K), TMOH(K),

\& TMALO2(K), DENEXP(K)

100 FORMAT (I7, 3X, 5F10.0)

WRITE $(6,99)$ ICASE, TMNO3(K), TMNO2(K), TMOH(K),

\& TMALO2(K), DENEXP(K)

99 FORMAT (I4, 4F9.3,8X,F10.3,3X, 'ECHO INPUT')

$\mathrm{K}=\mathrm{K}+1$

C

GOTO 1

$2 \mathrm{KK}=\mathrm{K}-1$

$\mathrm{K}=1$

$\mathrm{T}=25.0$

C CALCULATED WATER DENSITY AT TEMPERATURE $=25 \mathrm{C}$

C USING QUADRATIC LAGRANGIAN INTERPOLATING POLYNOMIAL. RHOWAT $=(T-25) *.(T-60) * .1 . /((3.98-25) *.(3.98-60))+$.

\& $(T-3.98) *(T-60) * 0.99707 /.((25 .-3.98) *(25 .-60))+$.

\& $(T-3.98) *(T-25) * 0.98324 /.((60 .-3.98) *(60 .-25)$.

$\mathrm{T} 2=\mathrm{T} * \star 2$

SUM $1 A=0.0$

SUM $1 B=0.0$

SUM $2 A=0.0$

SUM $2 B=0.0$

C

C THESE CORRELATIONS ARE FROM SOHNEL AND NOVOTNY REFERENCE

$3 \mathrm{C}=\mathrm{TMNO}$ (K) + TMNO2 $(\mathrm{K})+\mathrm{TMOH}(\mathrm{K})+\mathrm{TMALO2}(\mathrm{K})$

C NaOH DENSITY AT SAME STRENGTH AS MIXED SOLUTION

RHONOH $=(4.916 E 1-9.064 E-2 * T+6.308 E-4 * T 2) * C$ 
$\&+(-4.907+1.633 \mathrm{E}-2 * \mathrm{~T}-1.041 \mathrm{E}-4 * \mathrm{~T} 2) *(\mathrm{C} * * 1.5)$

RHONOH=RHOWAT+RHONOH* $1 . E-3$

C NaNO3 DENSITY AT SAME STRENGTH AS MIXED SOLUTION

RHONO3 $=(6.298 \mathrm{E} 1-2.382 \mathrm{E}-1 * \mathrm{~T}+1.520 \mathrm{E}-3 * \mathrm{~T} 2) * \mathrm{C}$

$\&+(-4.138+6.626 \mathrm{E}-2 * T-4.208 \mathrm{E}-4 * T 2) *(C * * 1.5)$

RHONO3=RHOWAT+RHONO3* $1 . E-3$

C NaNO2 DENSITY AT SAME STRENGTH AS MIXED SOLUTION

RHONO2 $=(5.142 \mathrm{E} 1-3.362 \mathrm{E}-1 * \mathrm{~T}+4.079 \mathrm{E}-3 * \mathrm{~T} 2) * \mathrm{C}$

$\&+(-3.242+7.155 \mathrm{E}-2 * \mathrm{~T}-9.671 \mathrm{E}-4 * \mathrm{~T} 2) *(\mathrm{C} * \star 1.5)$

RHONO2=RHOWAT+RHONO2*1.E-3

C

$\mathrm{I}=1$

$\mathrm{RHO}(\mathrm{I})=1.450$

SALTWT $=$ TMOH $(K) *$ TMOLWT $(1)+$ TMN03 $(K) * T M O L W T(2)+T M N 02(K)$

C

\& *TMOLWT(3)+TMALO2(K)*TMOLWT(4)

C CALCULATE MOLALITY FROM MOLARITY USING ASSUMED, ITERATED DENSITY

4 TMOLAL $(1)=$ TMOH $(K) /($ RHO $(I) * 1$. E3-SALTWT $) * 1$. E3

TMOLAL $(2)=$ TMNO3 $(K) /($ RHO $(1) * 1$. E3-SALTWT $) * 1$. E3

TMOLAL $(3)=$ TMNO2 $(K) /($ RHO $(I) * 1 . E 3-S A L T W T) * 1 . E 3$

TMOLAL $(4)=$ TMAL02 $(K) /($ RHO (I) *1.E3-SALTWT $) * 1 . E 3$

TMOLSM=TMOLAL (1) +TMOLAL (2)+TMOLAL (3) +TMOLAL (4)

IF $\left(\mathrm{K}-10^{*}(\mathrm{~K} / 10)\right.$. EQ.1) WRITE $(6,98) \mathrm{K}$, I, RHOWAT,

\& RHO(I), SALTWT, (TMOLAL $(J), J=1,4)$, TMOLSM

c

98 FORMAT (2I6,3F9.3,3X,5F9.3,3X, 'TMOLAL S')

C THE PSISUM/PSIRHO IS THE MIXING RULE FROM PATWARDIAN AND KUMAR

PSI $(1)=1 . E 3 *$ TMOLAL $(1) /$ TMOLSM + TMOLAL $(1) *$ TMOLWT $(1)$

PSI $(2)=1$. E3 $*$ TMOLAL (2) $/$ TMOLSM + TMOLAL (2)*TMOLWT (2)

$\operatorname{PSI}(3)=1$. E $3 *$ TMOLAL (3) $/$ TMOLSM + TMOLAL (3)*TMOLWT (3)

PSI $(4)=1 . E 3 *$ TMOLAL (4)/TMOLSM + TMOLAL (4)*TMOLWT (4)

PSISUM $=$ PSI (1) +PSI (2)+PSI (3)+PSI (4)

C APPROXIMATION: NaA102 DENSITY ASSUMED TO BE NaNO3 DENSITY

PSIRHO=PSI (1)/RHONOH+PSI (2)/RHONO3+

\& PSI(3)/RHONO2+PSI(4)/RHONO3

$I=I+1$

RHO (I) $=$ PSISUM $/$ PSIRHO

IF $(K-10 *(K / 10) . E Q .1)$ WRITE $(6,97) K, I,(\operatorname{PSI}(\mathrm{J}), \mathrm{J}=1,4)$,

\& RHONOH, RHONO3, RHONO2, RHO(I-1), RHO(I)

$\mathrm{C}$

97 FORMAT $(2 \mathrm{I} 6,4 \mathrm{Fg} .3,3 \mathrm{X}, 5 \mathrm{Fg} .3,3 \mathrm{X}$, 'PSI RHOS RHO')

C DENSITY NOT CONVERGED? RECALCULATE MOLALITY FROM ITERATED DENSITY

IF (ABS(RHO(I)-RHO(I-1)),GT.1.E-4.AND. I.LT.25) GOTO 4

$\operatorname{DENMR}(K)=R H O(I)$

WATPRT $=($ RHO $(I) * 1000 .-S A L T W T) * 1 . E-3$

WTRFRC $=$ WATPRT $/$ RHO (I)

C

C DENFIT IS CORRELATION FROM REYNOLDS AND HERTING

DENF IT $(K)=1.017+5.87 \mathrm{E}-2{ }^{*} \mathrm{TMALO2}(\mathrm{K})-1.943 \mathrm{E}-2^{\star} \mathrm{TMOH}(\mathrm{K})-5.05 \mathrm{E}-4 *(25.0)$

$\&+4.59 \mathrm{E}-2 *(\mathrm{TMALO} 2(\mathrm{~K})+\mathrm{TMOH}(\mathrm{K})+\mathrm{TMNO3}(\mathrm{K})+\mathrm{TMNO} 2(\mathrm{~K}))$

\& $-8.83 \mathrm{E}-4 *(\mathrm{TMNO} 3(\mathrm{~K}) \star$ TMNO2 $(K))$

IF $(K-10 *(K / 10)$. EQ.1) WRITE $(6,96) \mathrm{K}, I$,

\& PSISUM, PSIRHO, RHO( 1 ), WATPRT, WTRFRC

96 FORMAT $(2 \mathrm{I} 6,5 \mathrm{Fg} .3,3 \mathrm{X}$, 'PSISUM WTRFRC') 


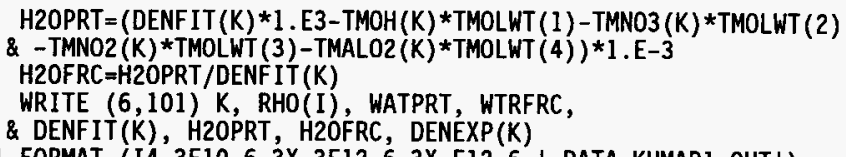

101 FORMAT (I4,3F10.6,3X,3F12.6,3X,F12.6,' DATA KUMAR1.OUT')

SUM1A $=S U M I A+R H O(I)-D E N E X P(K)$

SUM2A $=$ SUM2A+( (RHO (I) -DENEXP $(K)) * * 2)$

SUMIB $=$ SUM $1 B+D E N F I T(K)-D E N E X P(K)$

SUM2B $=S U M 2 B+((D E N F I T(K)-D E N E X P(K)) * \star 2)$

$\mathrm{K}=\mathrm{K}+1$

C

IF (K.LE.KK) GOTO 3

AVGA $=$ SUM1A/FLOAT (KK)

SDEVA $=$ SQRT ( (SUM2A-FLOAT $(K K) \star A V G A * * 2) / F L O A T(K K-1))$

$A V G B=S U M 1 B / F L O A T(K K)$

SDEVB $=S Q R T(($ SUM2B-FLOAT (KK) *AVGB**2)/FLOAT $(K K-1)$ )

WRITE $(6,102) \mathrm{KK}$, AVGA, SDEVA, AVGB, SDEVB

C

102 FORMAT (14,2F12.6,3X,2F12.6, ' AVG, SDEV (MIX, FIT) ')

SUM $1 A=0.0$

SUM $1 B=0.0$

SUM2A $=0.0$

SUM $28=0.0$

DO $5 \mathrm{~K}=1, \mathrm{KK}$

SUM $1 A=$ SUM1A+DENMR $(K)$

SUM2A $=$ SUM2A+ (DENMR $(K) * \star 2)$

SALTWT $=$ TMOH $(K) *$ TMOLWT $(1)+$ TMNO3 $(K) * T M O L W T(2)$

\& +TMNO2 (K) *TMOLWT (3) +TMALO2 (K) *TMOLWT (4)

WTRFRC $=(($ DENMR $(K) * 1000 .-$ SALTWT $) * 1 . E-3) / D E N M R(K)$

SUM1B $=$ SUM1B+WTRFRC

SUM2B $=$ SUM2B $+($ WTRFRC $* * 2)$

5 CONTINUE

AVGA=SUM1A/FLOAT (KK)

SDEVA=SQRT ((SUM2A-FLOAT (KK)*AVGA**2)/FLOAT $(K K-1)$ )

AVGB=SUM1B/FLOAT (KK)

SDEVB $=$ SQRT ( (SUM2B-FLOAT (KK)*AVGB**2)/FLOAT $(K K-1)$ )

WRITE $(6,103)$ KK, AVGA, SDEVA, AVGB, SDEVB

C

103 FORMAT (I4,2F12.6,3X,2F12.6,' AVG, SDEV (RHO-L, RHOH20/RHO-L)')

C AT RHO-L $=0.997070$, THE RHOH20/RHO-L IS 1.000000 (CASE 0)

C AT RHO-L $=1.386575$, THE RHOH20/RHO-L IS 0.560727 (CASE 9)

C SO (DELTA RHOH2O/RHO-L)/(DELTA RHO-L) IS

C $\quad(1.000000-0.560727) /(0.997070-1.386575)$

$\mathrm{DEL}=(1.000000-0.560727) /(0.997070-1.386575)$

WRITE $(6,104)$ DEL

104 FORMAT (3X, 'SLOPE OF (DEL RHOH2O/RHO-L)/(DEL RHO) ', F12.6)

SALTWT $=$ TMOH $(9) *$ TMOLWT $(1)+$ TMNO3 $(9) *$ TMOLWT (2)

$\&+$ TMNO2 $(9) *$ TMOLWT (3)+TMALO2 $(9) *$ TMOLWT (4)

WTRFRC $=(($ DENMR $(9) * 1000 .-$ SALTWT $) * 1 . E-3) / D E N M R(9)$

DEL $=(1.0-W T R F R C) /($ RHOWAT-DENMR $(9))$

WRITE $(6,104)$ DEL

END 
FORTRAN Computer Coding for Calculating $35 \mathrm{HLW}$ Tank Analyzed Liquids

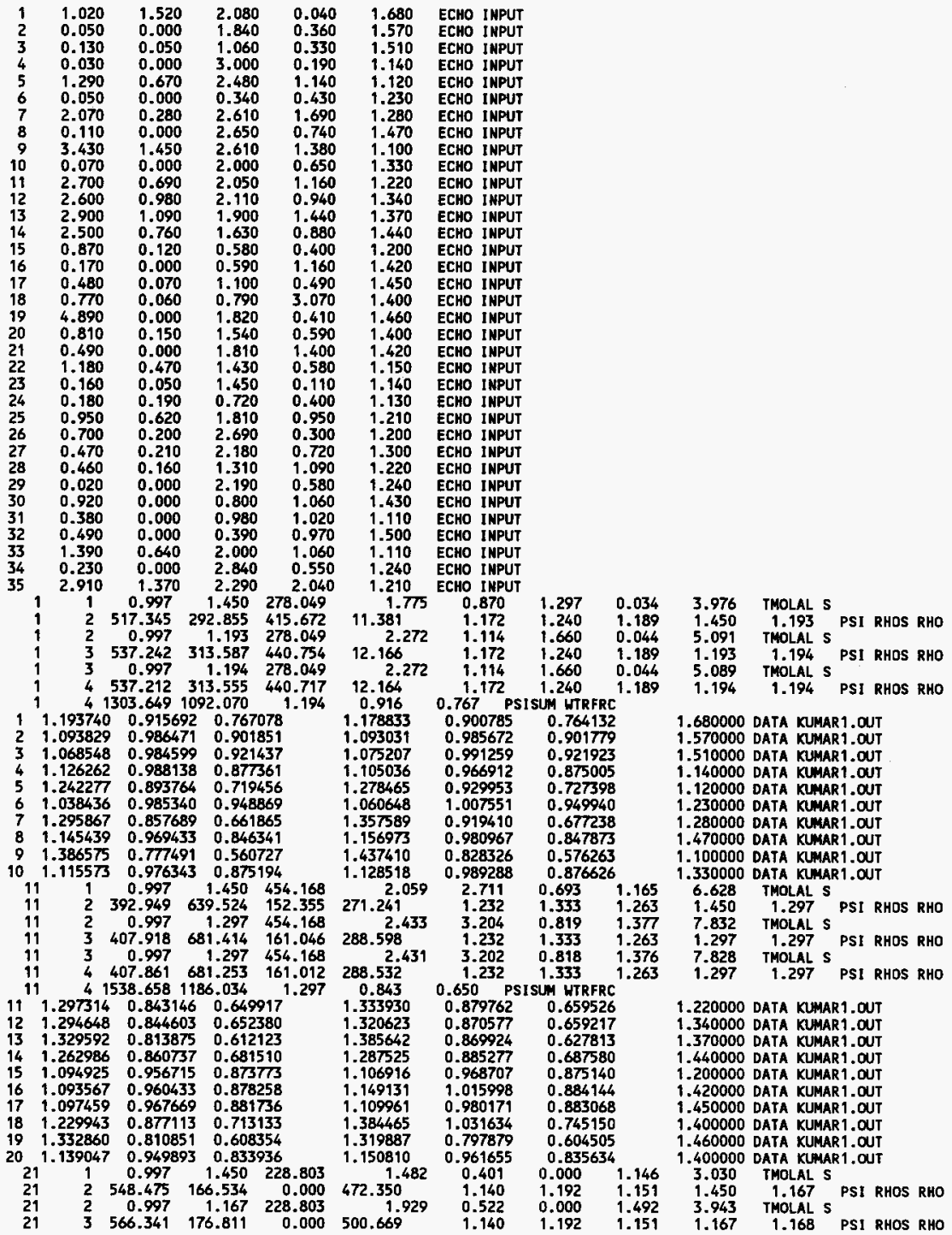


WHC-SD-WM-ER-531 REV 0

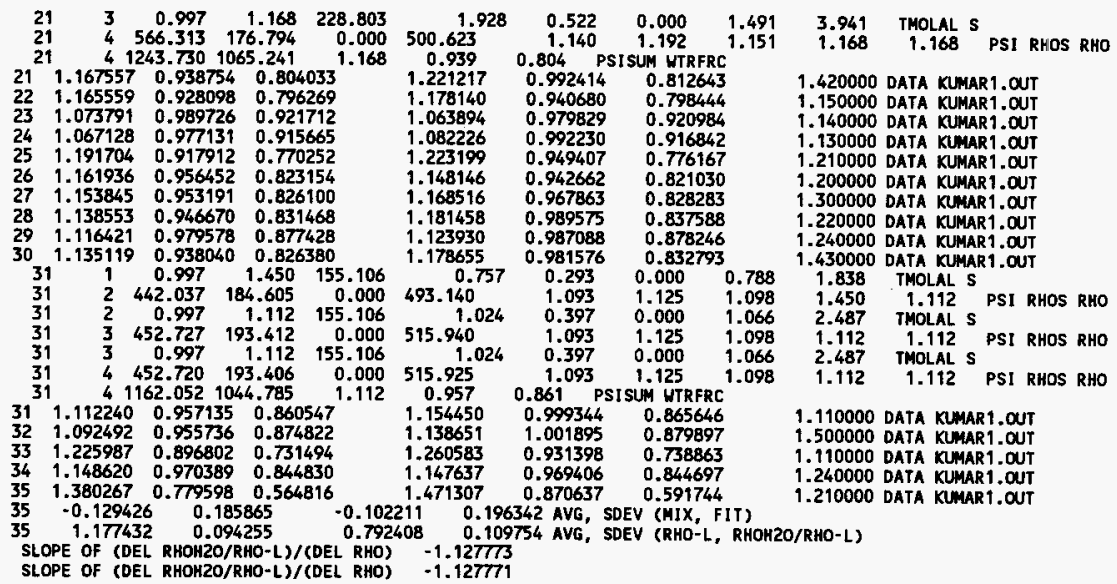




\section{REFERENCES}

Patwardhan, V. S. and Anil Kumar, 1993, "Thermodynamic Properties of Aqueous Solutions of Mixed Electrolytes: A New Mixing Rule," AIChE Journal, $39: 711,714$.

Patwardhan, V. S. and Anil Kumar, 1986, "A Unified Approach for Prediction of Properties of Aqueous Mixed-Electrolyte Solutions Part I: Vapor Pressure and Heat of Vaporization," AIChE Journa 7, 32:1419,1428.

Patwardhan, V. S. and Anil Kumar, 1986, "A Unified Approach for Prediction of Properties of Aqueous Mixed-Electrolyte Solutions Part II: Volume, Thermal and 0ther Properties," AIChE Journal, 32:1429,1438.

Reynolds and Herting, Solubilities of Sodium Nitrate, Sodium Nitrite, and Sodium Aluminate in Simulated Nuclear Waste, RHO-RE-ST-14 P, September 1984.

Söhnel, Otakar and Petr Novotnỳ, 1985, Densities of Aqueous Solutions of Inorganic Substances, Elsevier, New York, New York. 
WHC-SD-WM-ER-531 REV 0

APPENDIX D

REVIEW COMMENT RECORD FOR

INDEPENDENT REVIEW

D-1 
WHC-SD-WM-ER-531 REV 0

This page intentionally left blank.

D-2 


\begin{tabular}{|c|c|c|c|}
\hline \multirow{2}{*}{\multicolumn{2}{|c|}{ REVIEW COMMENT RECORD (RCR) }} & $\begin{array}{l}\text { 1. Date } \\
\text { May 6, } 1996\end{array}$ & $\begin{array}{l}\text { 2. Rousew No, } \\
\text { EMI - PNL }\end{array}$ \\
\hline & & 3. Project No. & $\begin{array}{l}\text { 4. Page } 1 \text { of } 2 \\
\text { a }\end{array}$ \\
\hline
\end{tabular}

\begin{tabular}{|c|c|c|c|c|}
\hline 5. Document Number (s)/Titile(s) & $\begin{array}{l}\text { 6. Prosram/Project/ } \\
\text { Bullding Number }\end{array}$ & 7. Reviewer & 8. Organlzation/Group & 9. Location/Phone \\
\hline $\begin{array}{l}\text { WHC-SD-WM-ER-531 REV } 0 \\
\text { Electromagnetic Induction probe } \\
\text { Calibration for Electrical } \\
\text { Conductivity Measurements and } \\
\text { Moisture Content Determination of } \\
\text { Hanford High Level Waste }\end{array}$ & $\begin{array}{l}\text { EMI Moisture } \\
\text { Monitor }\end{array}$ & $\begin{array}{l}\text { Dave Rector } \\
\text { Del Lessor }\end{array}$ & $\begin{array}{l}\text { PNNL/Fluid Dynamies } \\
\text { PNNL/Fluid Dynamies }\end{array}$ & $\begin{array}{l}\text { ISB1 } / 240 / \mathrm{RCHN} \\
372-4530 \\
\text { ISB } 1 / 243 / \mathrm{RCHN} \\
375-2382\end{array}$ \\
\hline
\end{tabular}

17. Comment Submittal Approval:

10. Agreenent with indicated comment disposition(s)

11. CLOSED

Organization Maneser (Optional)

Dellewt L. Lesov

Rovienor/Point of Contect

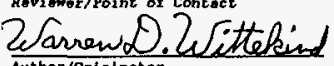

Thun 7996 Dellut P. Anor

$\operatorname{man}_{\text {Date }}, 1,996$ Reviewer/Point of Contact suthor/Orisinator

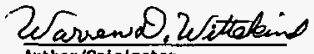
Author/Originator

12. 13. Comment(s)/Discrepancy(s) (Provide technical justification for Iten the comment and detalled recomendetion of the sction requlred to the comment and detsiled recomendation of the setion
corract/ rosolve the discrepancy/problem indicated.)

1. While Archie's Law probably provides a useful functional form for the moisture-vs-conductivity relation, the highly ionic and highly soluble saltcake may require different parameters than the only slightly soluble geologic materials for which parameters have been determined. We think that

the report should include a recommendation for an experimental determination of Archie' $s$ Law parameters for a highly ionic, highly soluble porous material, unless conductivity-vs-moisture information can be found for such material. Parameters determined for geologic salt formations might be satisfactory.

\begin{tabular}{|c|c|c|}
\hline $\begin{array}{l}\text { 14. Hold } \\
\text { Point }\end{array}$ & 15. D1sposition (Frovide justification it nOT accepted.) & 16. Status \\
\hline & $\begin{array}{l}\text { Yes. The suggestion for a demonstration } \\
\text { test, along with laboratory determination of } \\
\text { porosity, interstitial liquid electrical } \\
\text { conductivity, and free water mass fraction } \\
\text { as a proof-of-principal is accepted. This } \\
\text { will be worked on as time, schedule and } \\
\text { project resources permit. }\end{array}$ & $\begin{array}{l}\text { closed, } \\
\text { ERR }\end{array}$ \\
\hline
\end{tabular}




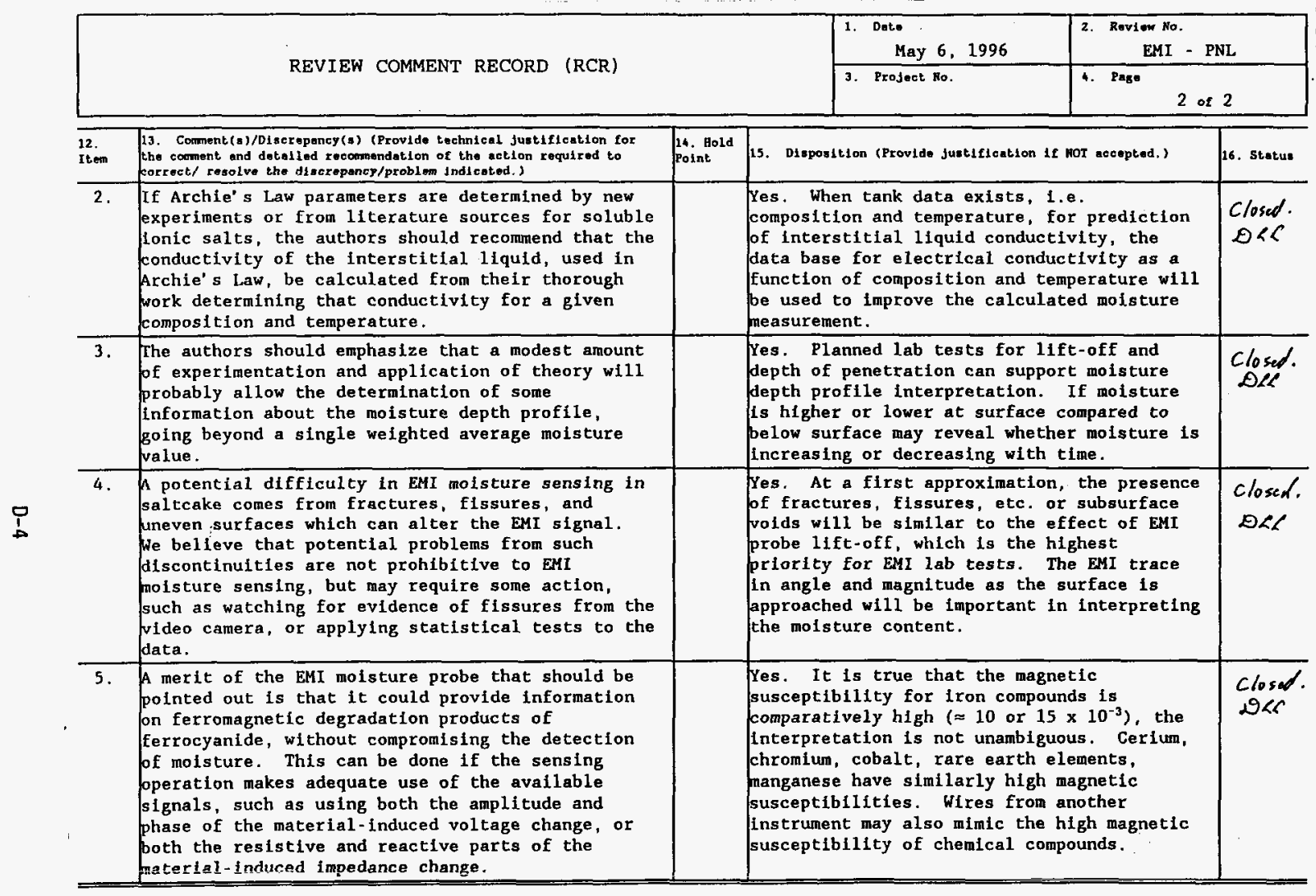




\section{Electromagnetic Induction Probe}

\section{Calibration for Electrical} Conductivity

Measurements and

Moisture Content

Determination of

Hanford High Level

Waste

Prepared for the U.S. Department of Energy

Assistant Secretary for Environmental Management

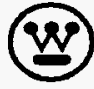

Westinghouse

Hanford Company Richland, Washington

Management and Operations Contractor for the

U.S. Department of Energy under Contract DE-AC06-87RL 10930

Approved for public release; distribution is unlimited 
LEGAL DISCLAMER

This report was prepared as an account of work sponsored by an agency of the United States Government. Neither the United States Government nor any agency thereof, nor any of their employees, nor any of their contractors, subcontractors or their employees, makes any werranty, express or implied. or assumes any legal liability or responsibility for the accuracy, completeness, or any third party's use or the results of auch use of any information, apparatus, product, or process disclosed, or represents that its use would not infringe privately owned rights. Reference herein to any specific commercial product, process, or service by trade name, trademark, manufacturer, or otherwise, does not necessarily constitute or imply its andorsement, recommendation, or favoring by the United States Government or any agency thereof or its contractors or subcontractors. The views and opinions of authors expressed herein do not necessarily state or reflect those of the United States Government or any agency thereof.

This report has been reproduced from the best available copy.

Printed in the United States of Americe

DISCLM-2.CHP (1.91) 


\section{DISTRIBUTION}

\section{Number of copies}

20

Westinghouse Hanford Company
H. Babad
J. M. Bates
R. J. Cash
R. D. Crowe
K. L. Drury
G. T. Dukelow
R. V. Harris, Jr.
R. L. Hockey
K. D. Lambert
D. L. Lessor
J. E. Meacham
R. E. Raymond
D. R. Rector
T. I. Stokes
G. F. Vargo, Jr.
A. E. Waltar
W. T. Watson
W. D. Wittekind
Central Files (2)
Original + 1 Copy

S7-14

K7-15

S7-14

HO-32

H5-09

S7-14

K5-26

K5-25

HO-32

K7-15

S7-14

S7-12

K7-15

L6-37

H5-09

$\mathrm{HO}-32$

$\mathrm{H} 0-32$

$\mathrm{HO}-32$

$+8-04$

A3-88 
WHC-SD-WM-ER-531 REV 0

This page intentionally left blank.

Distr-2 